DIW BERLIN

Discussion

Papers
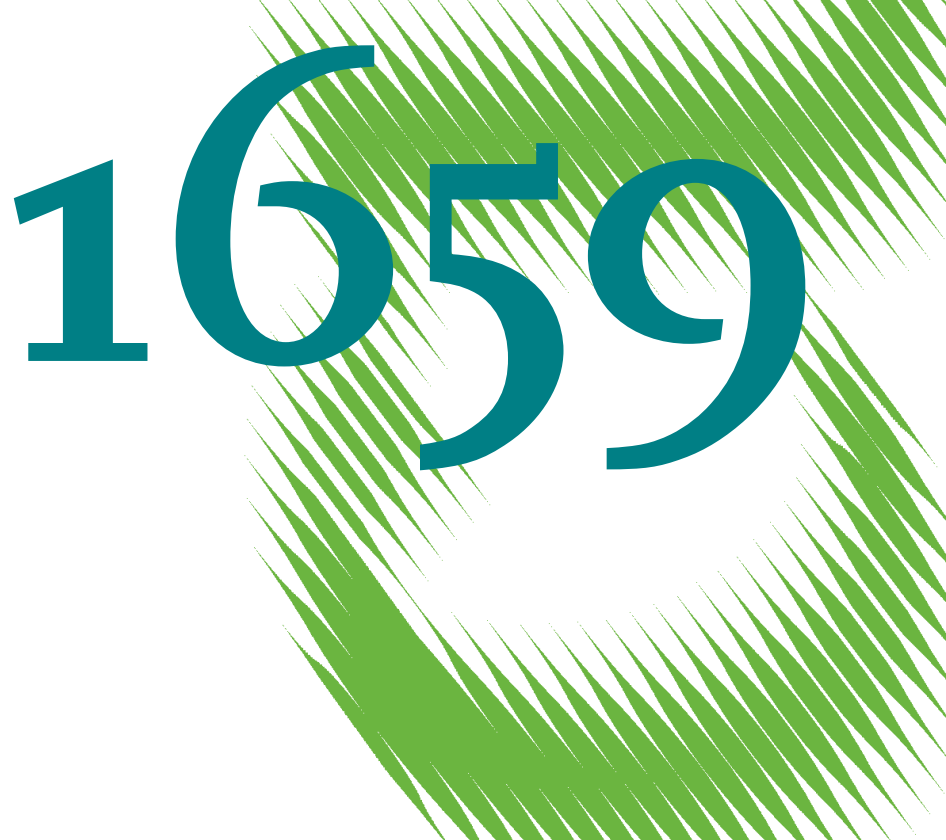

MMI

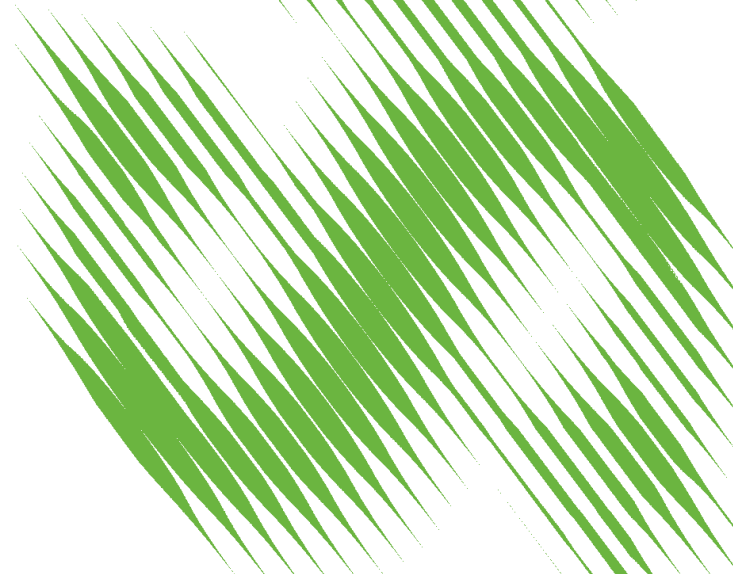

A Spatial Electricity Market Model for the Power System of Kazakhstan 
Opinions expressed in this paper are those of the author(s) and do not necessarily reflect views of the institute.

IMPRESSUM

(C) DIW Berlin, 2017

DIW Berlin

German Institute for Economic Research

Mohrenstr. 58

10117 Berlin

Tel. +49 (30) $89789-0$

Fax +49 (30) $89789-200$

http://www.diw.de

ISSN electronic edition 1619-4535

Papers can be downloaded free of charge from the DIW Berlin website:

http://www.diw.de/discussionpapers

Discussion Papers of DIW Berlin are indexed in RePEc and SSRN:

http://ideas.repec.org/s/diw/diwwpp.html

http://www.ssrn.com/link/DIW-Berlin-German-Inst-Econ-Res.html 


\title{
A spatial electricity market model for the power system of Kazakhstan
}

\author{
Makpal Assembayeva ${ }^{\mathrm{a}, *}$, Jonas Egerer ${ }^{\mathrm{b}, \mathrm{e}}$, Roman Mendelevitch $^{\mathrm{c}, \mathrm{d}, *}$, Nurkhat Zhakiyev $^{\mathrm{a}}$ \\ ${ }^{a}$ Nazarbayev University, National Laboratory Astana, Laboratory Energy, Ecology and Climate, 53 Kabanbay batyr ave., \\ 010000 Astana \\ ${ }^{b}$ Technische Universität Berlin, Workgroup for Infrastructure Policy (WIP), Straße des 17. Juni 135, 10623 Berlin \\ ${ }^{c}$ German Institute for Economic Research (DIW Berlin), Dept. Energy, Transport, Environment, Mohrenstr. 58, 10117 \\ Berlin \\ ${ }^{d}$ Humboldt Universiät zu Berlin, Resource Economics Group, Unter den Linden 6, 10999 Berlin \\ ${ }^{e}$ Friedrich-Alexander-Universität Erlangen-Nürnberg, Chair of Economic Theory, Chair of Industrial Organization and \\ Energy Markets, and Energie Campus Nürnberg (EnCN), Lange Gasse 20, 90403 Nürnberg
}

\begin{abstract}
Kazakhstan envisions a transition towards a green economy in the next decades which poses an immense challenge as the country heavily depends on (hydro-)carbon resources, for both its economy and its energy system. In this context, there is a lack of comprehensive and transparent planning tools to assess possible sustainable development pathways in regard to their technical, economic, and environmental implications. We present such a tool with a comprehensive techno-economic model of the Kazakh electricity system which determines the hourly least-cost generation dispatch based on publicly available data on the technical and economic characteristics of power plants and the transmission infrastructure. This modeling framework accounts for the particularities of the Kazakh electricity system: i) it has a detailed representation of combined heat and power, and ii) line losses are endogenously determined using a linear approximation. Model results are examined for a typical winter week (with annual peak load) and a typical summer week (with the hour of lowest annual load) presenting regionally and temporally disaggregated results for power generation, line utilization, and nodal prices. In an application to market design, the paper compares nodal and zonal pricing as two possible pricing schemes in Kazakhstan for the envisioned strengthening of the dayahead market. In general, the model can be readily used to analyze the least-cost dispatch of the current Kazakh electricity system and can be easily expanded to assess the sector's development. Among others, possible applications include investment in transmission lines and in the aging power plant fleet, scenarios and policy assessment for emission reduction, and questions of market liberalization and market design.
\end{abstract}

JEL codes: C61; D47; Q41

Keywords: Kazakhstan; Central Asia; Electricity sector; Techno-economic modeling; Transmission network; ELMOD

\footnotetext{
${ }^{*}$ Corresponding author

Email addresses: makpal.assembayeva@nu.edu.kz (Makpal Assembayeva), rmendelevitch@diw.de (Roman Mendelevitch)
} 


\section{Introduction}

The energy sector of Kazakhstan faces many challenges but also opportunities in the upcoming decades. It could foster its role as a transit hub with the development of transmission infrastructure linking Russia, Central Asia, and China. Kazakhstan, with its reliance on oil exports and coal-fired power generation has to find its place in a world which moves towards a sustainable energy supply. And last but not least, the energy sector might follow a pathway towards a more transparent and competitive market design. Thorough analyzes on these developments in Kazakhstan require qualitative and quantitative research to which this paper contributes focusing on the electricity sector.

In the time of the Soviet Union, the electricity system of Kazakhstan was split between the northern regions with large coal generation capacities (connected to the Russian network) and the Central Asian Power System (CAPS) in the south which relied on regional cooperation on water (and hydro power) management of river basins. Despite significant oil reserves, there was no development of an oil industry on larger scale. After the breakdown of the Soviet Union had caused a severe economic downturn, international investments, mainly in the oil sector, allowed Kazakhstan to restore its economy and to provide funding for improving infrastructure and living conditions. In the 1990s, Kazakhstan accomplished privatizations of formerly state owned companies and promoted unbundling of integrated utilities in the energy and other sectors (even though there has been some re-nationalization since). However, the economy continues to strongly rely on oil revenues due to its low level of diversification and it is closely linked to the Russian economy through the Eurasian Economic Union (Konkakov and Kubayeva, 2016).

The economic downturn in the 1990s had a strong impact on the electricity sector as dwindling demand levels resulted in the shutdown of half the generation capacity and the decay of the remaining capacity. In addition, with the independence of Kazakhstan, the national electricity system was split in three separate transmission networks. While the regional cooperation with its southern neighbors in the CAPS collapsed almost completely in electricity trade and river basin management, Kazakhstan gradually enforced the national transmission system, e.g., connecting its southern and northern network by a $500 \mathrm{kV}$ transmission line in 2009 (KAZENERGY Association, 2016). The cooperation with Russia remains significant in the operation of the electricity system even though annual trade levels are very volatile over years. The western network still is not connected directly to the rest of Kazakhstan and only linked to the Russian system.

While electricity demand had recovered to the levels seen before 1990 in 2014, levels shifted from regions with a traditional strong industrial basis (the industry GDP share decreased from 25 to 19 percent between 2000 and 2014 (OECD/IEA, 2016)) to the commercial sector, mainly in larger cities, and to the oil producing regions. These developments affect the regional distribution of electricity demand. Non-oil industrial activity is concentrated in the north-eastern regions of East Kazakhstan, Karagandy, and Pavlodar, with strong ties to the Russian economy while oil and gas resources and associated industries are based in the western regions of Mangystau, Atyrau, and Western Kazakhstan. The other regions are still characterized by agricultural and commercial activities. So far, the demand growth of electricity in the respective regions could be met by reactivation and retrofitting of mostly old and mothballed generation units and the enforcement of the transmission system.

In 2013, Kazakhstan's 2050 strategy (Kazakh government, 2013b) expected a continuous growth of electricity demand requiring imminent investment in new and therefore more expensive coal-fired power plants (e.g., project of Balkhash coal power plant). While wind and solar generation capacities were expected to increasingly supply the growing electricity demand, a reduction of carbon emissions in the electricity sector was not envisioned before 2030. Large capacities of combined heat and power (CHP) plants are a distinctive feature of the electricity sector in Kazakhstan. Here, the 2050 strategy suggests a fuel switch from coal to natural gas in CHP plants in proximity to cities to reduce local air pollution. Contrary to the projection of fast growing electricity demand, levels stagnated after 2013 and, together with lower electricity exports to Russia, excess generation capacity remains available in the system. At the same time, investments in new coal generation capacity was postponed. In the end, this development could allow a more sustainable pathway for the electricity sector as time might play in favor of renewable technologies.

This example illustrates the importance to conduct qualitative and quantitative research on the development scenarios of the energy sector. Compared to other regions (e.g., Europe and North America) 
the literature on the energy and electricity sector in Kazakhstan is rather limited (see Section 2). A better understanding of the technical system characteristics and the underlying energy economics is vital for a transparent discussion and decision making. This requires the development of tools for technical and economic system analysis such as the techno-economic electricity sector model in this paper.

In addition to scenario analysis for future generation and transmission development with a sufficient spatial representation, questions of market design receive increasing attention in Kazakhstan. Since 2000, the Kazakhstan Operator of Electric Power and Capacity Market (KOREM) has the task to organize the centralized electricity wholesale market (Kazakh government, 2000). Energy supplying organizations (ESOs) have been established in 2004, serving as regional single buyers of electricity and as regional monopoly supplier for end consumers (KOREM, 2016b). Since 2013, the Natural Monopolies Regulation Agency of Kazakhstan (NMRA) sets up regional tariffs for end consumers which are further differentiated by the annual level of electricity consumption and by the temporal consumption pattern. The tariffs are fixed for three years with the possibility for annual adjustment (Kazakh government, 2013a). Being introduced for tracking energy usage and creating incentives for investments in energy efficiency, some argue that their inflexible structure and uncertainty about future adjustments hamper positive effects (KAZENERGY Association, 2014). Average end consumer prices for electricity were in the range between $10.0 \mathrm{KZT} / \mathrm{kWh}$ and $19.5 \mathrm{KZT} / \mathrm{kWh}$ in 2016 , with highest prices in the region Kostanay and lowest prices in Aktau (ENEGRYPROM.KZ, 2016). Despite formal vertical unbundling of generation and transmission companies, mid- and long-term bilateral contracts accounted for $90 \%$ of the total transactions and the day-ahead market for the remaining share (KOREM, 2016b). Electricity supply is mostly covered from regulated fixed tariff contracts with generation companies, with only $3 \%$ of the demand covered by market trades, in 2015 . In addition to the feed-in tariff scheme for renewable generation which is in place since 2014 (KOREM, 2016a), there are efforts to enforce stronger market-based elements in the electricity sector with the plan to have regional auctions for renewable capacities (Uatkhanov, 2016) and by pricing carbon emissions. These instruments foster a gradual low-carbon transformation of the sector as required by the Green Growth Strategy 2050 (Kazakh government, 2013b).

While quantitative research is important for the understanding of system and market operation and for possible changes in the market design, it relies on transparency and the availability of system data. In Kazakhstan, the lack of a functioning wholesale market, low competition levels, and limited transparency are obstacles for publicly accessible information. However, system and market data are important to improve electricity sector models which can be applied to reveal inefficiencies and potentials for improvement in the sector design. This work makes one step in the direction of more transparency by providing a spatial electricity sector model for Kazakhstan which is able to optimize the power plant dispatch of the electricity system. The basic version of the model determines the least-cost generation dispatch and includes a nodal representation of the transmission system of Kazakhstan, providing additional insights in power sector planning and in system transformation for decision makers.

As of 2016, the Kazakh electricity sector remains heavily regulated on generation tariffs and electricity prices. The model setup, optimizing for the least-cost generation dispatch, assumes the existence of a central entity which determines efficient power plant operation, and provides hourly locational marginal prices. Possible steps in that direction could be the introduction of a power exchange or of an independent system operator. In an application on market design, the paper compares the nodal pricing regime to a spatial aggregation of the nodal representation into four price zones in Kazakhstan.

For future work, the model framework can be easily extended, e.g., by generation and transmission investment analyzing scenarios for sector transformation, by representing the cross-border integration of neighboring countries for questions of coordination, or by cross-sectoral analysis.

The remainder is structured as follows. Section 2 provides a literature review, followed by the mathematical model description in Section 3. Section 4 describes the input data, Section 5 the model results and Section 6 concludes. 


\section{Literature Review}

\subsection{Modeling the energy and electricity sector}

Mathematical models of the energy sector provide an important contribution to the analysis and the understanding of a sector which is of particular importance for the low-carbon transformation. A large portfolio of models exist in the academic literature.

Pfenninger et al. (2014) classify models according to the different challenges they address. ${ }^{1}$ They differentiate between energy system models for normative scenarios, energy system simulation models for forecasts, power systems and electricity market models for analyzing operational decisions and qualitative and mixed-methods for narrative scenarios. Energy system models such as PRIMES (Capros et al., 1998), MARKAL (Fishbone and Abilock, 1981), EFOM (Finon, 1981) or POLES (Criqui, 1996) are able to convey the "big picture" of what is happening in different linked sectors of an energy system. These technologyoriented models focus on the energy conversion system, on the demand-side (e.g., efficiency measures) as well as on the supply side (e.g., wide range of generation technologies). Hall and Buckley (2016) present a review of energy system models used in the UK and made a classification of these models. The advantages of this type of models are that they cover several sectors, linking them through endogenous fuel substitution. They are solved by optimization techniques when minimizing system costs or maximizing the overall welfare. Another class of models focuses on accounting and simulation e.g., LEAP (Heaps, 2008). These models provide a detailed representation of the current state of an energy system and can be applied to evaluate energy policies and energy plans.

Apart from energy system models, there is a large strain of literature that employs partial equilibrium models to assess one particular market, e.g., the electricity market. This allows for analyzing non-cooperative firm behavior in more detail (e.g., Cournot competition) by allowing the firms to strategically exploit their influence on the market price with their output decision. Moreover, different risk attitudes and explicit shadow prices can be easily incorporated in these settings. The models have been focusing on considerations of resource adequacy (Ehrenmann and Smeers, 2011), impact assessment of environmental regulation (Allevi et al., 2013), renewables obligations and portfolio standards (see e.g., Gürkan and Langestraat 2014 and Chen and Wang 2013), or coordination of congestion management by transmission system operators (Kunz and Zerrahn, 2015). Huppmann and Egging (2014) present a large-scale multi-fuel investment model formulated as an equilibrium model that tries to bridge the gap between sector models and enegy system models. However, equilibrium models are limited in their representation of technical characteristics of the electricity sector which are important for a detailed model representation.

By contrast, a large body of literature focuses on the particularities in the electricity sector. These models can be categorized in simulation, optimization, and equilibrium models. Another differentiation is possible by their assumptions on the market design and their temporal and geographic system representation (Ventosa et al., 2005). Examples for optimization models in the context of regulated electricity market are the DIETER model (Zerrahn and Schill, 2015) or ELMOD model (Leuthold et al., 2012). These models represent market behavior taking a social planner or cost-minimizing perspective to assess investments in electricity infrastructure, congestion management, and market designs. Other models focus on uncertainty, balancing, and intra-day markets (Rintamäki et al., 2016) and on the spatially resolution (Koltsaklis et al., 2014), the temporal resolution (Mikkola and Lund, 2016), or both of them (Razeghi et al., 2016; Nahmmacher et al., 2016).

The insights provided by a technology-rich electricity market model can also be used to reevaluate the results of more aggregated models. Deane et al. (2012) establish a soft-link between an energy system and a power system model to study the systematic errors that occur when using energy system models for power system design. Abrell and Rausch (2016) link a general equilibrium model and an electricity dispatch model to examine the implications of transmission expansion and renewable energy penetration in Europe.

\footnotetext{
${ }^{1}$ For a detailed topology of different modeling approaches for energy and power systems also see Després et al. (2015).
} 


\subsection{Existing models for Kazakhstan and Central Asia}

For the region of Kazakhstan and Central Asia, the development of energy system and electricity sector models has only started in the 2000s and the literature, in particular the documentation of the models, is just beginning to evolve (see Table 1). It builds mostly around applications of the MARKAL/TIMES and the LEAP model framework. The existing literature covers a range of topics including projections of greenhouse gas (GHG) emissions (Goldstein and Tosato, 2008), evaluations of climate policy instruments (Inyutina et al., 2012), assessment of the energy saving potential for Kazakhstan (Sarbassov et al., 2013; Gómez et al., 2014) and analysis of opportunities for emission reduction investments in Central and West Asia regions (ABIT Associates et al., 2014). To quantify the effects of energy subsidies reforms in Kazakhstan, OECD (2014) develops a partial-equilibrium model. De Miglio et al. (2014) use a MARKAL/TIMES model to evaluate the economic profits in cooperation between Central Asia and Caspian countries through the differentiation of their export routes. Kerimray et al. (2016) analyze climate change and energy efficiency policies according to the results of TIMES-Kazakhstan model. The main conclusion of this study was to find ways how to achieve the governmental targets of decreasing GHG emissions in Kazakhstan. Atakhanova and Howie (2007) develop an econometric model for estimating electricity demand in the industrial, residential, commercial, and other sectors of Kazakhstan until 2015.

Models which have been used for Kazakhstan are bottom-up energy system models. They cover multiple sectors and consider spatially aggregated regions as well as either a single or a small set of seasonal time slices. While this approach is sufficient to analyze the development of a fossil-fuel-based power system, the increasing share of fluctuating renewable generation in electricity supply requires models with a high temporal and spatial resolution. These aspects are better addressed in sectoral models which are also favorable in representing the technical and inter-temporal characteristics of storage technologies, electricity flows in the transmission network, and the volatile character of regional electricity load.

Several studies on the power system of Kazakhstan and Central Asia have employed electricity sector models. McKinney and Savitsky (2001) have created the EPIC (Environmental Policy and Institutions for Central Asia) modeling system with the aim to optimize the regulation of water resources and the regional distribution of the associated hydroelectricity of the Aral Sea. Later Antipova et al. (2002) used this model to solve water and energy problems of the Kyrgyz energy system considering national benefits and regional water requirements. Egerer et al. (2014) present a first bottom-up electricity sector model for Kazakhstan which optimizes the generation dispatch, electricity flows, and network investment with a nodal representation of the high-voltage transmission system. The study analyzes scenarios for the the electricity system of Kazakhstan for 2030 and 2050.

\begin{tabular}{l|c|l} 
Type of the model & Region & Character \\
\hline \hline ENPEP [1] & KAZ & Estimation of the GHG emissions in electricity and heat systems \\
Econometric model [2] & KAZ & Electricity demand forecast \\
MARKAL-MACRO [3] & KAZ & GHG mitigation potential \\
LEAP [4] & KAZ & Evaluation of climate policy instruments \\
MARKAL/TIMES [5] & KAZ & Analysis of investments for GHG emission reduction \\
MARKAL/TIMES [6] & KAZ & Analysis of governmental policies \\
Partial-equilibrium model [7] & KAZ & Effects of energy subsidies reforms \\
LEAP [8] & CWA & Analysis of investments for GHG emission reduction \\
MARKAL/TIMES [9] & CACC & Evaluation of economic benefits of cooperation \\
ELMOD-KAZ [10] & KAZ & Nodal electricity sector model with line investment
\end{tabular}

Table 1: List of energy systems and sector models ${ }^{2}$

\footnotetext{
${ }^{2}$ Abbreviations: KAZ (Kazakhstan), CWA (Central and West Asia), CACC (Central Asia and Caspian countries). References: [1] Kazakh Institute of Climate and Environment Monitoring (1996), [2] Atakhanova and Howie (2007), [3] Goldstein and Tosato (2008), [4] Inyutina et al. (2012), [5] Sarbassov et al. (2013); Gómez et al. (2014), [6] Kerimray et al. (2016), [7] OECD (2014), [8] ABIT Associates et al. (2014), [9] De Miglio et al. (2014), [10] Egerer et al. (2014).
} 


\section{Mathematical formulation of the electricity sector model}

The model in this paper represents an electricity sector model for Kazakhstan which minimizes variable generation costs for electricity generation given technical, spatial, and temporal constraints. The detailed spatial representation represents an electricity market with locational marginal pricing on the level of network nodes. The model follows the approach presented in Leuthold et al. (2012) and Egerer (2016) and in particular extends the ELMOD-KAZ model by Egerer et al. (2014).

This section is organized as follows: the objective function and the nodal energy balance are defined in Section 3.1, Section 3.2 describes the representation of CHP plants, Section 3.3 introduces the DC load flow approach, Section 3.4 the implementation of transmission losses, and Section 3.5 states a possible model aggregation to price zones. The notation is listed in 6 .

\subsection{Basic model}

The objective function of the model in Eq. 3.1a minimizes variable generation cost of the electricity dispatch, including marginal costs $M C_{p}$ for conventional electricity generation $e n_{p t}$ by generation units $p$ and cost of lost load VOLL for energy not served ens $s_{n t}$.

The energy balance in Eq. 3.1b ensures that the sum of conventional electricity generation, generation from renewable energy sources $R E S_{n t}$, net input from the transmission network $n i_{n t}$, potential imports $I M_{n t}$, and energy not served is equal to electricity demand $D E M_{n t}$ and potential exports $E X_{n t}$ at every network node $n$ and in every time slice $t$ (Kirchhoff's first law). Renewable generation is assumed to be nondispatchable and implemented with assumptions on nodal hourly generation levels.

Constraints on maximum and minimum available generation capacity for conventional power plants are given in Eqs. 3.1c-3.1d, where $C A P_{p}^{\mathrm{P}+}$ is the maximum and $C A P_{p}^{\mathrm{P}-}$ the minimum of the technically operational capacity of a generation unit, $A V_{p t}$ states its hourly availability, and $o n_{p t}$ is a binary variable defining if the unit is in operation or not in the respective hour.

$$
\begin{array}{cc}
\min _{e n_{p t}, e n s_{n t}} c=\sum_{p t}\left(e n_{p t} M C_{p}\right)+\sum_{n t}\left(e n s_{n t} V O L L\right) & \\
\sum_{p \in P_{n}} e n_{p t}+R E S_{n t}+n i_{n t}+I M_{n t}+e n s_{n t}=D E M_{n t}+E X_{n t} & \forall n, t \\
e n_{p t} \leq C A P_{p}^{\mathrm{P}+} A V_{p t} o n_{p t} & \forall p, t \\
e n_{p t} \geq C A P_{p}^{\mathrm{P}-}{ }^{o} n_{p t} & \forall p, t
\end{array}
$$

\subsection{Representation of combined heat and power}

The electricity and the heat sector can be linked on the supply side (CHP plants) and on the demand side (electric heating). The representation of these links can be implemented in electricity sector models at different levels of technical detail. On the supply side, a detailed representation of the heat market would provide most insight in the technical and operational constraints of CHP plants but requires specific information on the regional heat markets and related infrastructure (e.g., boilers for heat only generation). Advanced modeling approaches allow for optimization of combined heat and power operation and assessment of optimal installation size (Fang and Lahdelma, 2016). Such approaches are suitable for operational decisions in regional heat markets but difficult to implement in an optimization model at the electricity system level. One possibility to abstract from a detailed representation of the heat system requires assumptions on power plant operation, e.g., Davidson et al. (2016) are fixing the minimum operation requirements for CHP plants according to assumptions for winter and summer hours.

The model in this paper applies the approach of Davidson et al. (2016) by setting minimum generation requirements and must-run operation $\left(o n_{p t}=1\right)$ for CHP plants (Eq. 3.2), where $C A P_{p t}^{\mathrm{H}-}$ is the minimum 
operational capacity of a CHP generation unit due to minimum heat output levels. Together with the technical minimum operation level, either $3.1 \mathrm{~d}$ or 3.2 are the binding constraint depending on the level of $C A P_{p}^{\mathrm{P}-}$ and $C A P_{p t}^{\mathrm{H}-}$.

In this representation, the heat output itself is not described in the model. On the demand side, the model assumes exogenous hourly electricity demand levels which include demand for electric heating.

$$
e n_{p t} \geq C A P_{p t}^{\mathrm{H}-}{ }^{\circ} n_{p t} \quad \forall p \in P_{c h p}, t
$$

\subsection{Representation of the transmission network and line contingency}

Following Schweppe et al. (1988), the direct current load flow (DCLF) representation (i.e., a simplification and linearization of $\mathrm{AC}$ power flow) determines power flows in the model according to technical and physical line flows constraints. Line flows $p f_{l t}$ and net input $n i_{p t}$ are defined in the Eqs. 3.3a-3.3b while Eq. 3.3c limits the flow on every transmission line. $H_{l n}$ calculates from the line's resistances and reactances and its start and end node while $B_{n k}$ further aggregates this information to network nodes. The DC load flow formulation requires defining one slack node $\hat{n}$ with $\theta_{\hat{n} t}=0$ for each network.

$$
\begin{array}{rlr}
p f_{l t} & =\sum_{n}\left(H_{l n} \theta_{n t}\right) & \forall l, t \\
n i_{n t} & =\sum_{k}\left(B_{n k} \theta_{k t}\right) & \forall n, t \\
-C A P_{l}^{\mathrm{L}} & \leq p f_{l t} \leq+C A P_{l}^{\mathrm{L}} & \forall l, t
\end{array}
$$

The TSO, responsible for ensuring reliable system operation, does not allow to use the full thermal capacity of a transmission line but reserves a transmission reliability margin (TRM) to account for inherent uncertainty in system conditions and the need for operating flexibility (Zhang et al., 2004). The power flow limit $C A P_{l}^{\mathrm{L}}$ follows this argumentation and includes a TRM of $20 \%$ reducing line capacities to $80 \%$ of their respective thermal limit. The TRM tries to approximate network operation which is n-1 secure, i.e., the possibility to compensate the outage of one component/line by the remaining system without causing the break-down of the system.

\subsection{Transmission losses}

The Kazakh electricity system transmits electricity over long distances causing significant losses in the high-voltage network, which reached $6 \%$ of total generation in 2015 (KEGOC, 2016). Losses on transmission lines depend on the line's technical characteristics (its material, length, and voltage level) and have a nonlinear relation to the load flow level.

The literature provides various approaches to include transmission losses in the context of locational marginal pricing models. Losses on transmission lines are commonly assigned to the adjacent network nodes in the model representation (Hu et al., 2010). In the context of transmission expansion planning and dispatch problems, variable line losses with a non-linear relation to load flow levels are often omitted. Variable line losses can be approximated with a fixed estimated loss ratio for each transmission line in the nodal energy balance. Instead, Babu and Harini (2016) present a model where losses are balanced at each node and the impact on line flow is represented. Santos and Diniz (2011) apply an advanced iterative methodology for representing losses using line loss cuts for relevant operational points. In Helseth (2012), losses are represented by distributing a share of total losses to each node and quadratic nodal losses are approximated by iteratively adding linear constraints. Zhang et al. (2013) use a 3-segment piece-wise linear approach for transmission losses to study the electricity system of New Zealand verifying their results with an AC load flow analysis. The original quadratic loss curve is replaced by a piece-wise linear loss function which allows for implementing losses in a linear model framework. 
This paper applies the latter approach in a simplified version with only one linear segment to approximate line losses for the Kazakh electricity system. Nodal transmission losses calculate by the sum of half the linearized losses on all adjacent lines. This approximation overestimates losses for low lines utilization and, vice versa, underestimates losses for high lines utilization. The model implements line losses with two equations. Eq. 3.4a captures the absolute value of losses on a line calculated as line flow $p f_{l t}$ multiplied with a line specific loss factor which is calculates by the line's length and voltage level. Eq. 3.4b provides an extended energy balance including the distribution of line losses to the adjacent nodes.

$$
\begin{aligned}
& l o s s_{l t}^{+}-l o s s_{l t}^{-}=L C_{l} p f_{l t} \quad \forall \quad l, t \\
& \sum_{p \in P_{n}} e n_{p t}+R E S_{n t}+n i_{n t}+I M_{n t} \\
& -0.5 \sum_{l, n \in A_{l n}}\left(\operatorname{loss}_{l t}^{+}+\operatorname{loss}_{l t}^{-}\right)+e n s_{n t}=D E M_{n t}+E X_{n t} \quad \forall \quad n, t
\end{aligned}
$$

\subsection{Zonal pricing}

Contrary to nodal pricing, zonal pricing provides an alternative for the market representation of spatial system constraints. While in theory, nodal pricing is considered the first best, zonal pricing can increase liquidity by providing larger markets within each zone. However, zonal markets are less suitable for highly meshed systems as they abstract from the load flow characteristics and ignore all internal lines capacity by providing an aggregated zone-to-zone net transfer capacity (NTC) into the market. In the case of Kazakhstan, the three regions West, North, and South in Figure 1 could provide reasonable price zones. To highlight the network situation between the regions Pavlodar and Karaganda the zonal setting in this paper includes the additional zone Middle which consists only of Karaganda region.

The representation of price zones in the nodal electricity sector model requires an aggregation to one energy balance per zone in Eq. 3.5a replacing the nodal balance as well as the introduction of a NTC between two connected zones in Eq. 3.5b instead of the representation of line flows with the DCLF approach.

$$
\begin{array}{ccc}
\sum_{p \in P_{z}} e n_{p t}+\sum_{n \in N_{z}}\left(R E S_{n t}+n i_{n t}+I M_{n t}+e n s_{n t}\right) & =\sum_{n \in N_{z}}\left(D E M_{n t}+E X_{n t}\right)+\sum_{x} z f_{z x t} & \forall, t \\
z f_{z x t} \leq N T C_{z x} & \forall & z, t
\end{array}
$$




\section{Input data}

\begin{tabular}{l|l|c} 
Type & Data description & Reference $^{3}$ \\
\hline \hline Network & - Topology according to network map & {$[1]$} \\
& - Technical parameters for overhead power lines & {$[2]$} \\
\hline Demand & - Load level for Kazakhstan & {$[3]$} \\
& - Spatial allocation to network nodes & {$[4]$} \\
& using statistics on industrial demand and & {$[5]$} \\
\hline Generation & using statistics on population distribution & {$[6]$} \\
& - Power plant list for Kazakhstan & {$[7]$} \\
& - Cost data for fossil fuels & {$[8]$} \\
\hline Import/Export & - Coal transport cost & {$[9]$} \\
\hline Availability & - Cross-border flows with Kazakhstan & {$[10]$}
\end{tabular}

The bottom-up techno-economic electricity sector model for Kazakhstan applies a detailed spatial representation of the power system, therefore requiring information on technical, geographic, temporal, and economic parameters. In the following, this section describes the dataset: Section 4.1 focuses on network data, Section 4.2 on electricity demand, Section 4.3 on power plant data, Section 4.4 on economic parameters, and Section 4.5 on cross-border trade with neighboring countries. To a large extend, the dataset relies on the publicly available data sources summarized in Table 2.

\subsection{Network data}

The electricity sector model of this paper represents the transmission system of Kazakhstan on a nodal level which allows for a wide variety of techno-economic analysis. This approach requires detailed geographic and technical information on the transmission network, namely the location of the substations and the topology and technical parameters for the high-voltage transmissions lines. Figure 1 presents the model implementation of the topology of the transmission network of Kazakhstan according to the transmission system operator's (KEGOC) grid map (KEGOC, 2014c). The network of KEGOC consists of 310 transmissions lines between $35 \mathrm{kV}$ and $1150 \mathrm{kV}$ which have a total length of about 25,000 km (KEGOC, 2014c, 2016). In general, KEGOC divides the transmission system of Kazakhstan into nine regional centers for operational principles (security in network operation) and also uses the administrative division of Kazakhstan in 14 districts. This paper follows the latter regional representation on district level and also states results at a more aggregated level, i.e., for the three regions West, South, and North as illustrated in Figure 1.

\footnotetext{
${ }^{3}$ References: [1] KEGOC (2014c), [2] Faibisovich et al. (2006); Kiessling et al. (2003), [3] KEGOC (2014b); KAZENERGY Association (2016), [4] KEGOC (2016), [5] Committee of Statistics of Kazakhstan (2015), [6] KEGOC (2014a), [7] KOREM (2016a,b), [8] McKinsey (2012), [9] KEGOC (2014b); Supreme Eurasian Economic Council (2015), [10] HydroMetCenter (2012); NASA (2005).
} 


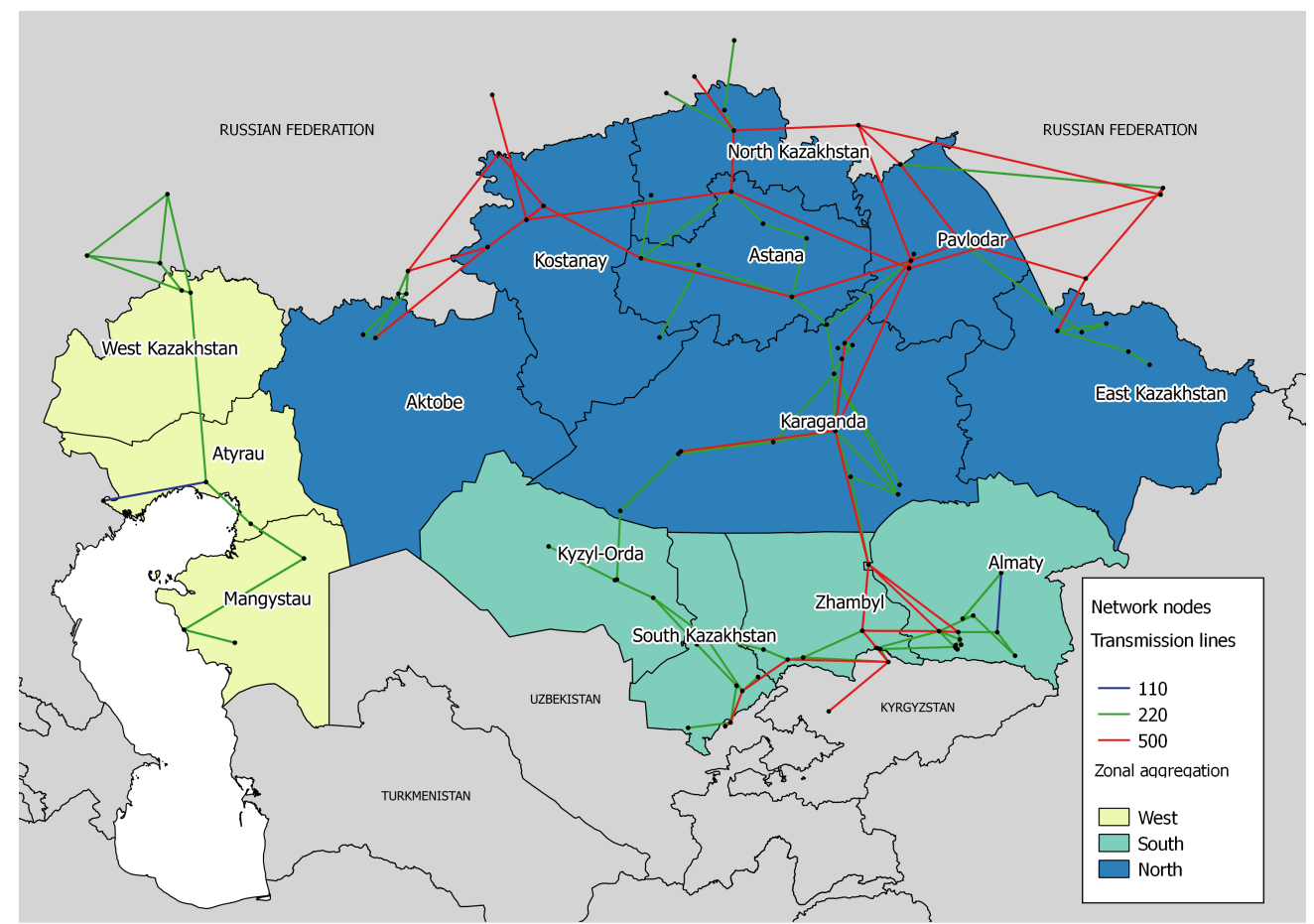

Figure 1: Model representation of the high-voltage transmission network in Kazakhstan

In the dataset of this paper, the power grid of Kazakhstan is represented by 97 network nodes and 193 high-voltage transmission lines between $220 \mathrm{kV}$ and $1150 \mathrm{kV}$ and selected $110 \mathrm{kV}$ lines for better representation of electricity consumption in the Almaty region. Each network node represents a substation including its geographical location and can by connected to electricity demand and generation units. Thereby, substations which have one transmission line passing through and which are not the end-point of their line are not included in the network representation and their generation and demand is allocated to the closest network node (i.e., either an end-point of a line or an intersection of several lines). The model approach abstracts from a representation of technical information on transformers as they are neglected in the implementation of the DC load flow linearization. In addition to 74 network nodes in Kazakhstan, the dataset also contains 23 external nodes in neighboring countries which allows for the implementation of cross-border flows.

The input data on transmission lines contains information on 193 individual connections: 40 lines with the voltage level of $500 \mathrm{kV}$ (including four lines of $1150 \mathrm{kV}$ currently operated at $500 \mathrm{kV}$ ), 126 lines with $220 \mathrm{kV}$, four lines with $110 \mathrm{kV}$, and 23 cross-border lines to external nodes. Technical characteristics of the transmission lines such as voltage level, line length, number of circuits, power flow limits, and loss factors have been taken from KEGOC (2016). Assumptions on the additional line parameters reactance, resistance, and thermal limits are made for each line according to its voltage level (Kiessling et al., 2003; Faibisovich et al., 2006). ${ }^{4}$ Of the 23 cross-border lines, 18 connect the power system to Russia, 4 to Kyrgyzstan and 1 to Uzbekistan. The total number of lines that are situated on Russian territory but connect two substations in Kazakhstan is 20. For Kyrgyzstan there are six such lines and five for Uzbekistan.

Following Faibisovich et al. (2006) the loss factor per $100 \mathrm{~km}$ is in range of $0.5-1 \%$ for lines at $500 \mathrm{kV}$ and between $3.5-4.5 \%$ for lines of $220 \mathrm{kV}$ and $110 \mathrm{kV}$. The constant loss factor in the model is $1 \%$ for lines of $500 \mathrm{kV}$ and $4 \%$ for lines of lower voltage level.

\footnotetext{
${ }^{4}$ The thermal limit of $500 \mathrm{kV}$ lines is reduced to have a more realistic representation of the line characteristics in Kazakhstan. In the model their maximum capacity for one transmission system is 1,100 MW (i.e., $880 \mathrm{MW}$ considering the $20 \%$ TRM) and $340 \mathrm{MW}$ for a line of $220 \mathrm{kV}$.
} 


\subsection{Electricity demand}

After years of growth, national electricity demand reached 89.17 TWh in 2013 and stagnated thereafter on similar levels with $90.85 \mathrm{TWh}$ in 2015 (KEGOC, 2016). This demand is not distributed evenly throughout Kazakhstan and shows a strong seasonal variation. The largest electricity consumers with $45 \%$ of total power consumption are located in the northern and eastern regions (Figure 2a). The dataset on electricity demand builds upon hourly national consumption data and annual consumption for each of the 14 administrative regions in 2013 (KEGOC, 2014b) and assumptions on residential and industrial demand. This paper makes assumptions on hourly national demand for one winter and one summer week as KEGOC does not publish hourly demand series (Figure 10). ${ }^{5}$ In general, the 168 hours per winter and summer week assume seasonal and hourly characteristics in electricity demand, an annual peak demand of about $13 \mathrm{GW}$ in the winter week, and the lowest off-peak demand with about $8 \mathrm{GW}$ in the summer week.

For the spatial demand allocation, hourly data is distributed to the 14 regions based on annual regional demand and assumptions on residential and industry demand shares. Residential demand for electricity is aggregated in 24 consumption nodes representing 24 cities of Kazakhstan (Figure 2b). They include two cities of national significance (Almaty and Astana), fourteen administrative city centers, and eight cities with a population over 70,000 (Committee of Statistics of Kazakhstan, 2015). The demand curve of the residential sector is calculated based on the consumption rate of three regions of Kazakhstan with high population density and a low share of industrial demand (i.e., the regions Kyzylorda, North Kazakhstan, and West Kazakhstan). Industrial demand is based on the demand of fifteen major companies constituting $35 \%$ of the overall energy consumption of Kazakhstan (KEGOC, 2016). According to KAZENERGY Association (2016), the industry sector is composed of plants that produce non-ferrous metals, mine iron ore, coal and oil, do water treatment, supply electricity for railroad operations, etc. We assume that the hourly demand pattern of this industries is steady. The residential and industrial demand nodes are geographically matched to the closest of the 74 network nodes (substation) in the high-voltage transmission system.

A group of objects (generation, demand or substation) that belongs to the same region and locates in the same area are grouped in one node.

(a) Annual demand by region

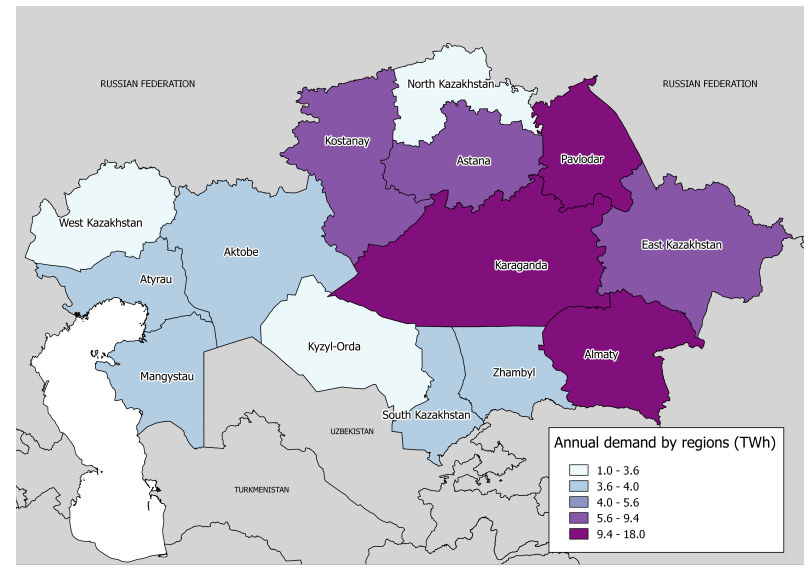

Figure 2: Spatial electricity demand for Kazakhstan in 2013 (b) Nodal demand shares

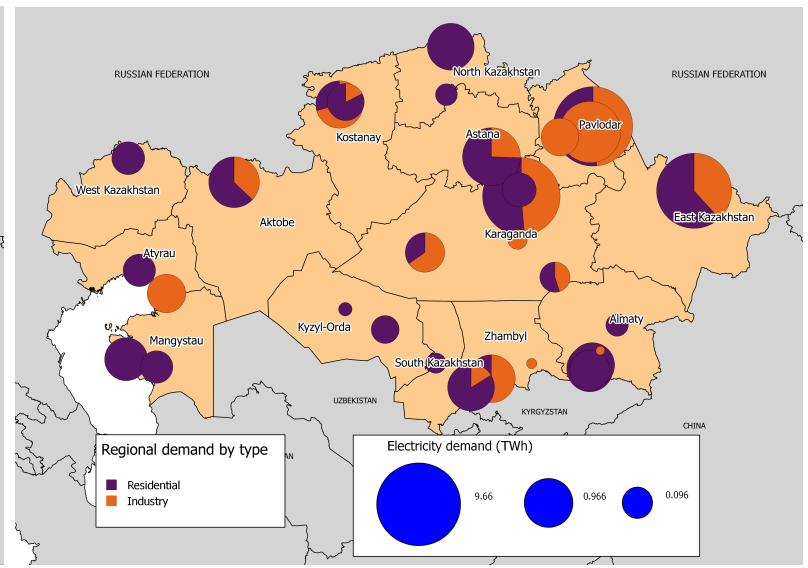

\subsection{Data on power plants}

The input data on generation capacity contains information on all 74 conventional power plants (by generating unit) in Kazakhstan which have a total installed capacity of 20.6 GW. Technical data includes

\footnotetext{
${ }^{5}$ The model can be easily extended to an hourly representation $(8760 \mathrm{~h})$ with the availability of hourly demand data.
} 
fuel type, generation technology, installed turbine capacity, efficiency factors, minimum load levels, seasonal availability factors, the geographic location, and the connecting network node.

As of 2016, the largest share of electricity generation in Kazakhstan relies on fossil fuels. The spatial distribution of conventional power plants illustrates a special characteristic of the electricity sector in Kazakhstan. Most of the electricity-only generation capacity is provided by coal power plants $(7.1 \mathrm{GW})$ in the north-east (Pavlodar) which are supplied by large local coal fields and i) power the local heavy industry and ii) feed surplus electricity into the high-voltage transmission grid. While coal fuels combined heat and power (CHP) plants for district heating in all demand centers in the north and east, natural gas powers most electricity-only and CHP plants in the south and all generation in the west (see Figure 3). Electricity-only power generation is dominated by few large installations (19 units with a total of $10.5 \mathrm{GW}$ ). CHP generation capacity makes up a large share of total installed capacity (40 power units with $7.5 \mathrm{GW}$ ). Therefore, its representation in the electricity sector model has strong implications on the results. Using historical data on heat output and making own assumptions, the model representation of CHPs is as follows: i) industrial CHPs operate at a constant level throughout the year providing a steady heat and therefore also power supply; ii) minimum generation requirements are defined for all other CHP units based on data of seasonal electric and heat output levels.

Renewable generation capacity is provided mainly by 15 hydro power plants with a capacity of $2.6 \mathrm{GW}$ and an annual generation output of 9.3 TWh in 2015 (KEGOC, 2016). The five largest hydro power plants are located at the Irtysh River in East Kazakhstan and many smaller ones in the mountains of the Almaty region. Their seasonal availability factors are calculated based on data provided by KEGOC (2014a).

Even though most regions in Kazakhstan promise a significant wind and solar potential (Karatayev and Clarke, 2016) electricity supply from wind and PV does not play a significant role in the Kazakh electricity system. The first capacities were brought online in 2015: 70.1 MW of wind, located in the regions North Kazakhstan and Akmola and at the border to Kyrgyzstan and $52.8 \mathrm{MW}$ of PV, located in the regions South Kazakhstan, Zhambyl, and Almaty. The model data is based on information for annual generation output of JSC Samruk-Energy (2016) and on historical data on wind speed and solar radiation. Wind speeds from meteorological stations (HydroMetCenter, 2012) are used to calculate hourly time series with availability factors for each network node. This information can be translated in power output of wind power plants using Weibull probability distribution functions. Solar radiation data from NASA (2005) is applied in a similar manner to calculated normal (Gaussian) distribution for the network nodes. The distribution functions are scaled to represent values of hourly availability between 0 and 1 . 


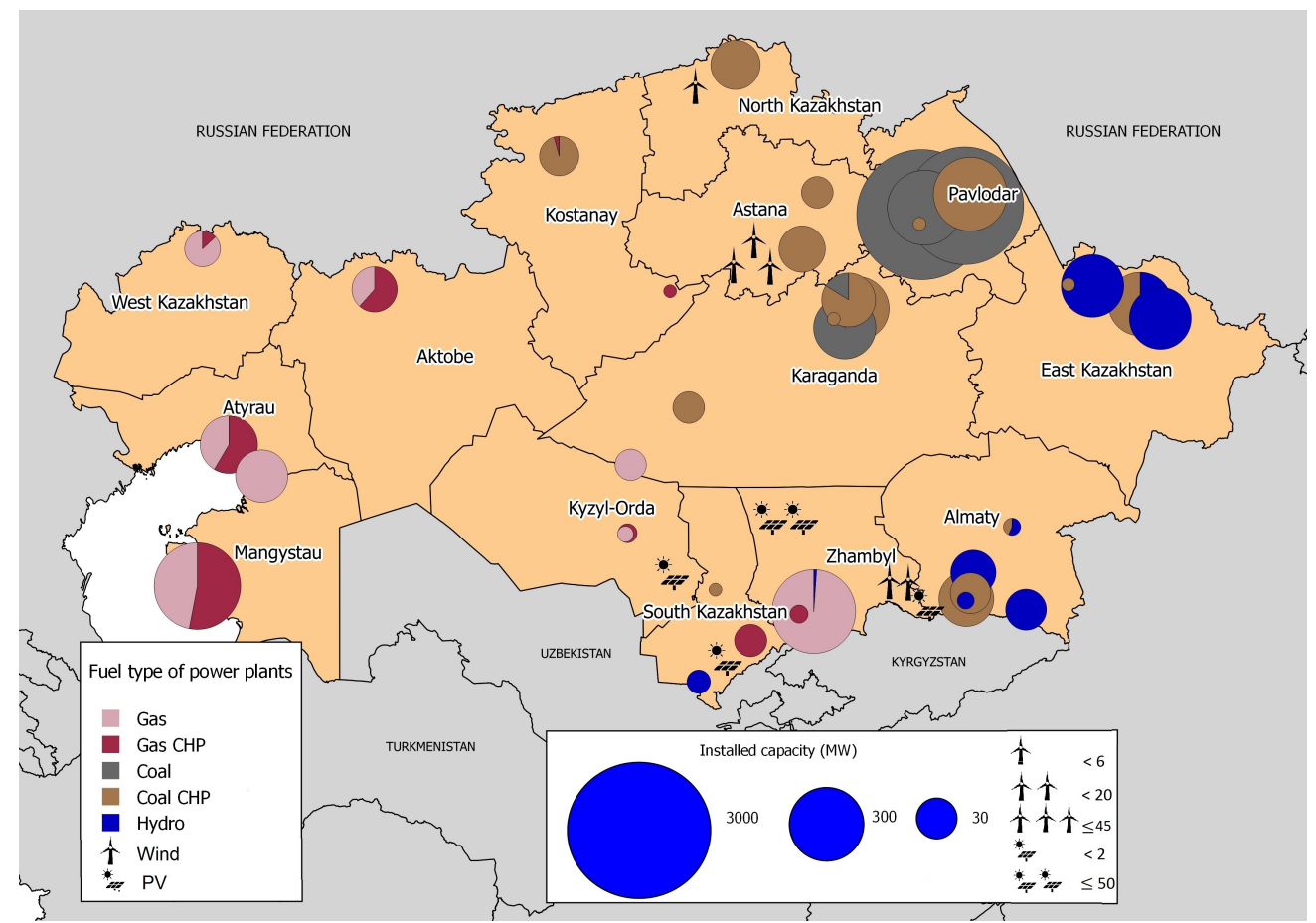

Figure 3: Power plants capacities in Kazakhstan of the year 2013 and renewable capacities in 2015

\subsection{Economic parameters}

Kazakhstan is a major producer and consumer of coal, accounting for around $4 \%$ of the world total coal reserves. Kazakhstan's coal is characterized by very low production cost compared to other CIS states (KAZENERGY Association, 2016). Coal with the lowest production cost is located in the Northern part of Kazakhstan but the final price for coal increases significantly (e.g., in Almaty region) with long distances from the mining region due to high rail transportation costs. Data on coal production and transportation cost which is used to calculate marginal generation cost for coal-fired generation units was taken from McKinsey (2012) and KOREM (2016a).

\begin{tabular}{|c|c|c|c|c|c|c|c|}
\hline Fuel & $\begin{array}{c}\text { Tech- } \\
\text { nology }\end{array}$ & Purpose & $\begin{array}{c}\text { Capacity } \\
\text { MW } \\
\end{array}$ & $\begin{array}{l}\text { Start } \\
\text { year }\end{array}$ & $\begin{array}{c}\text { Average } \\
\text { cap. factor } \\
\% \\
\end{array}$ & $\begin{array}{c}\text { Average } \\
\text { efficiency } \\
\%\end{array}$ & $\begin{array}{c}\text { Fuel } \\
\text { costs } \\
K Z T / k W h_{t h}\end{array}$ \\
\hline Coal & $\mathrm{ST}$ & & $663-4000$ & $1962-1980$ & 65 & 32 & $0.3-0.5$ \\
\hline Coal & $\mathrm{ST}$ & CHP & $12-1000$ & $1937-2009$ & 57 & 42 & $0.3-2.2$ \\
\hline Gas & GT & & $6-244$ & 1996-2012 & 58 & 33 & $1.8-2.2$ \\
\hline Gas & $\mathrm{ST}$ & & $460-1230$ & 1983-2006 & 28 & 34 & $1.8-2.2$ \\
\hline Gas & $\mathrm{ST}$ & CHP & $4-630$ & $1944-1981$ & 42 & 44 & $1.8-2.2$ \\
\hline Hydro & & & $2-702$ & 1928-2013 & 33 & 93 & \\
\hline
\end{tabular}

Table 3: Aggregated data on conventional power plants 
According to KAZENERGY Association (2016) Kazakhstan has around four trillion cubic meters of gas reserves. Nevertheless, gas consumption accounts only for $17.5 \%$ of the country's primary energy balance. Most of reserves are located in Western Kazakhstan and the gas pipeline network connects the West to the South but except for Kostanay not the North of Kazakhstan. The prices for natural gas vary significantly within the country with lower prices in the west (McKinsey, 2012).

Marginal generation cost from renewable energy sources, such as hydro, wind, and photovoltaic are assumed to be zero. Aggregated information on technical and economic characteristics of current Kazakh power plants are reported on the technology level in Table 3.

\subsection{Cross-border trade with neighboring countries}

In 2015, electricity transmission on the inter-regional level accounted for $37.89 \mathrm{TWh}$, where almost $10 \%$ of flows include transit services (Russia-Kazakhstan-Russia) rendered by the national operator (KEGOC, 2016). Electricity export and import between Kazakhstan and Kyrgyzstan was done only for irrigation water needs. The aggregated volume of exchanged electricity was $0.25 \mathrm{TWh}$, which was realized in the period from July until October 2015. Import volumes from Russia where at 1.5 TWh in 2015 and decreased by $7.3 \%$ compared to 2014 levels. At the same time, Kazakhstan exported 1.03 TWh to Russia in 2015, which represents a decrease of $67 \%$ compared to 2014 levels.

\section{Model results}

The results in this paper illustrate the functionality of the electricity sector model for Kazakhstan and provide an application with price zones. Section 5.1 describes the hourly generation dispatch with the lowest variable generation costs possible. The results are aggregated by technology for the two weeks with the hour of highest and lowest electricity demand. Section 5.2 discusses nodal results on network utilization and locational marginal prices for the average of both weeks, as well as for the summer hour with lowest demand and the winter hour with highest demand. Section 5.3 examines the possibility of introducing a market design with an aggregation of network nodes into four price zones which are derived from the insights of the nodal model results.

\subsection{National and regional generation dispatch by technology}

The hourly national generation dispatch in Kazakhstan for two selected weeks is illustrated in Figure 4. The two weeks represent a summer week with the hour of lowest national electricity demand and a winter week with the hour of peak demand. Hourly electricity generation and imports cover electricity demand, network losses, and exports.

The national hourly generation profile highlights the central role of hard coal and CHP plants (coal and gas) for electricity generation in Kazakhstan. Generation patterns for hydro power and electricity-only coal-fired power plants do not exhibit much seasonal variation. Electricity-only coal-fired power plants (with $15 \%$ higher generation output in the winter) cover about $48 \%$ of demand in the summer week and $42 \%$ in the winter week. Generation from wind and solar plays a minor role in total electricity generation in Kazakhstan as of 2015. ${ }^{6}$ Therefore, the largest difference in absolute seasonal generation levels can be observed for CHP plants which have to cover seasonal base-load heat demand resulting in a minimum must-run operation level. y Hourly variation of electricity load in the summer is mostly covered by coal-fired electricity-only power plants which have the lowest variable generation costs. In the winter week, these power plants also provide a significant share of the variability on the supply side. However, they must be complemented by more expensive gas turbine power plants due to higher overall demand levels and higher load variation between night and day. Compared to the summer week, CHP plants cannot provide additional peak load generation in the winter week. Due to higher base-load heat demand, they operate constantly at their maximum output level while additional heat-only boilers cover the peak heat demand.

\footnotetext{
${ }^{6}$ Respective average regional generation levels are reported in Figure 11 in the Appendix.
} 


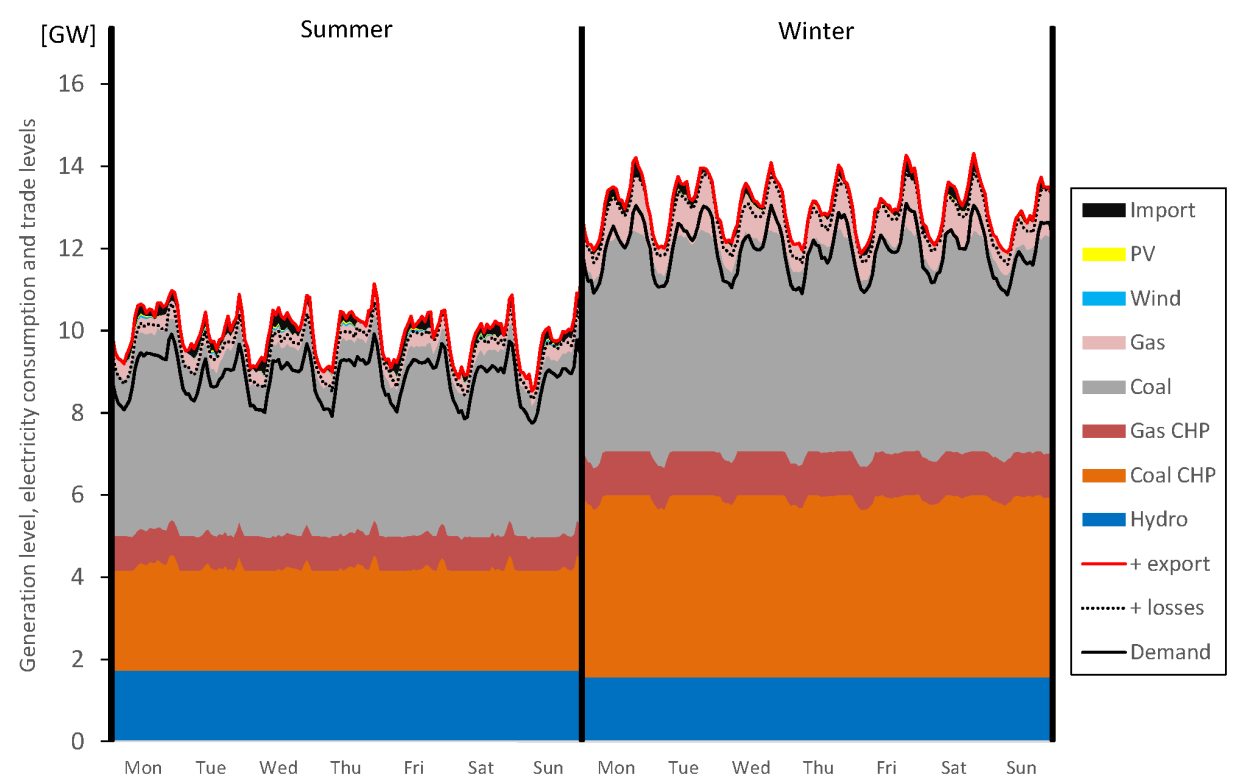

Figure 4: Hourly national generation dispatch (summer and winter week in 2015)

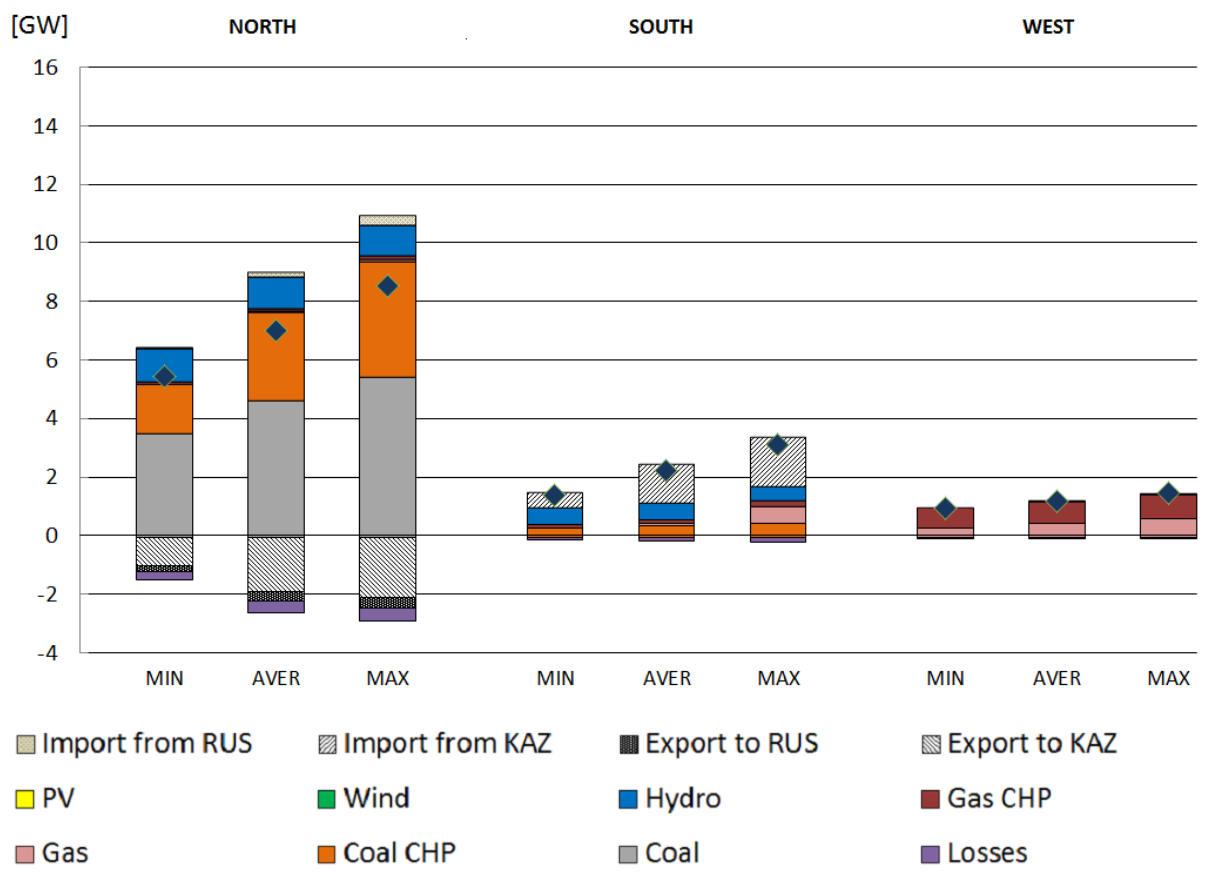

- Demand

Figure 5: Regional results for off-peak hour (MIN), peak hour (MAX), and average levels (AVER) 
Figure 5 presents zonal generation profiles for the hour of minimum, maximum, and average demand (of the two examined weeks). The least-cost generation dispatch sees excess generation from coal-fired electricity-only power plants in the North. This surplus supplies the South in all load situations and increases with electricity demand levels. ${ }^{7}$ In summer hours with low demand, the South relies (to a smaller extent) on imports from the north as it covers about half of its electricity demand with local hydro power and $30 \%$ with must-run CHP generation. While imports from the north are significantly higher in the winter, higher electricity demand in the South and import constraints in the transmission network require additional electricity generation from more expensive local gas-fired electricity-only power plants. The separate network in the West relies on electricity supply from natural gas firing in CHPs and electricity-only plants. While the CHP plants operate more constantly, electricity-only plants cover higher electricity demand levels during the day.

The average level of transmission line losses accounts for $6.8 \%$ of consumption. Hourly losses (relative to load) are somewhat higher in the summer and in off-peak hours and lower in winter hours with high demand. In total, significant line losses occur in West and North regions due to long distances and high transmission volumes (more precisely in the regions Atyrau, Karaganda and Pavlodar) and on the long transmission lines towards the South (between Karaganda and Kyzylorda).

\subsection{Locational marginal prices and utilization of transmission lines}

The nodal model results allow for insights in the utilization of transmission lines and the determination of potential bottlenecks in the network, as well as for economic indicators with locational marginal prices for Kazakhstan.

The results for average line utilization in Figure 6 indicate, that there are no permanent bottlenecks in the network and that most lines have an average utilization below $50 \%$. While gas-fired power generation causes higher average nodal prices in the separated network in the West, average nodal prices also differ between the northern and the southern nodes. Lowest nodal prices are observed in the northern part of the country (starting at about $1.2 \mathrm{KZT} / \mathrm{kWh}$ for mine-mouth coal-fired power plants in Pavlodar and rising to $2.5 \mathrm{KZT} / \mathrm{kWh}$ for more distant coal-fired power plants with higher fuel prices due to coal transportation costs or network losses) and increase from the southern (between $2.5 \mathrm{KZT} / \mathrm{kWh}$ and $3.7 \mathrm{KZT} / \mathrm{kWh}$ ) to the western nodes (peaking at $5.8 \mathrm{KZT} / \mathrm{kWh}$ ). These results suggest bottlenecks on some lines in the transmission system between the North and the South in certain hours. ${ }^{8}$

Results on line utilization and nodal prices for the hour of lowest load in the summer (Figure 7) show no congestion in the transmission network. Nodal prices have similar levels of about $1.4 \mathrm{KZT} / \mathrm{kWh}$ and deviate to the extent of transmission losses as must-run CHPs, hydro generation, and coal-fired generation in Pavlodar (setting the marginal price) cover electricity demand. Only the West of Kazakhstan experiences significantly higher prices of about $5.9 \mathrm{KZT} / \mathrm{kWh}$ due to continuous operation of gas turbine plants.

The peak load situation in the winter (Figure 8) shows higher nodal prices in the entire country. Nodal prices in the northern part of Kazakhstan increased by about $60 \%$ (compared to average levels) to about $3.7 \mathrm{KZT} / \mathrm{kWh}$. High demand results in line congestion on the north-south inter-connectors leading to a stronger increase of nodal prices in southern Kazakhstan up to $7.4 \mathrm{KZT} / \mathrm{kWh}$, which is five times the price of the low demand hour. Nodal prices do not increase in western Kazakhstan because gas turbine power plants remain the marginal generators. Electricity prices are lower than in southern Kazakhstan due to lower natural gas prices.

\footnotetext{
${ }^{7}$ A further disaggregation of generation by region, which can be found in Figure 11 in the Appendix, shows that excess supply is generated in Pavlodar, whereas the regions Aktobe and South Kazakhstan rely on imported electricity.

${ }^{8}$ Three lines (neglecting the western part) show average utilization levels close to the maximum of $80 \%$ considering a reliability margin of $20 \%$. These lines connect power generation in Pavlodar region: to the South, to an industrial demand center in Karaganda region (iron and steel factory ArcelorMittal Temirtau), and to Astana region.
} 
(a) Average utilization of transmission lines

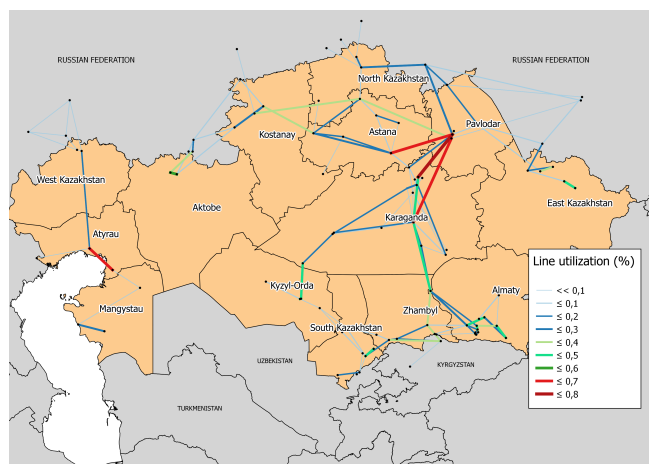

(b) Average value of electricity prices

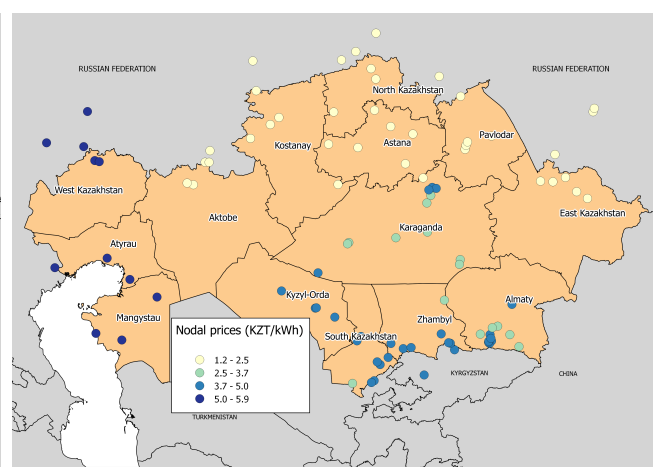

Figure 6: Average nodal results for all hours of the two weeks

(a) Line utilization

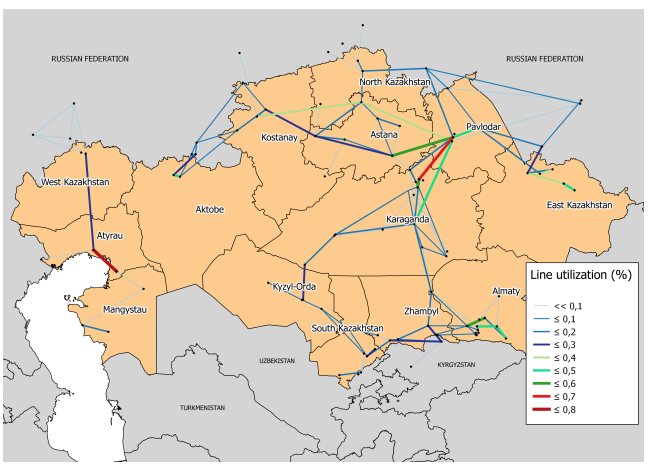

(b) Nodal prices

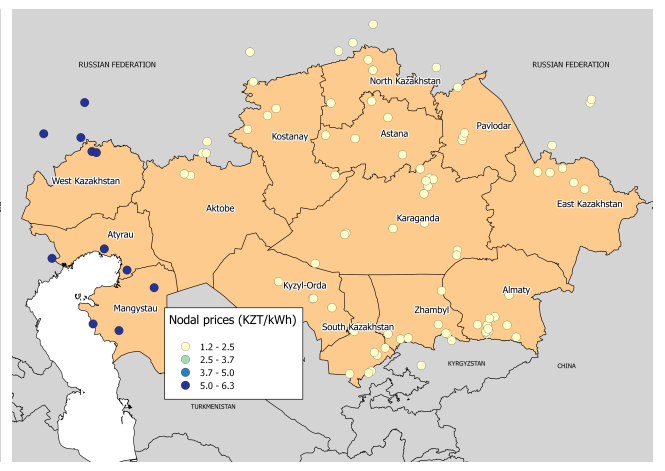

Figure 7: Summer hour with lowest demand level

(a) Line utilization

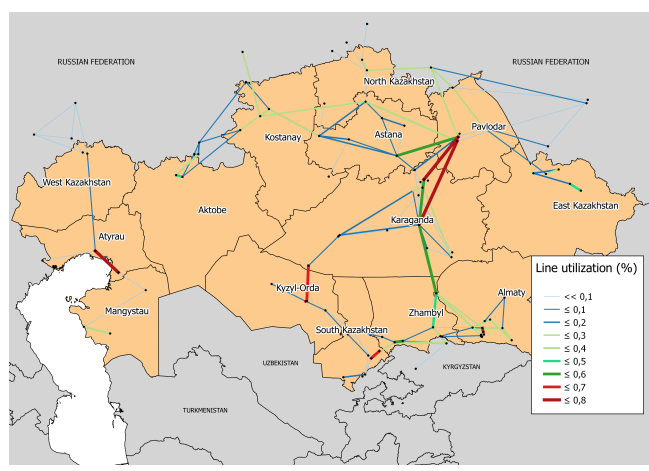

(b) Nodal prices

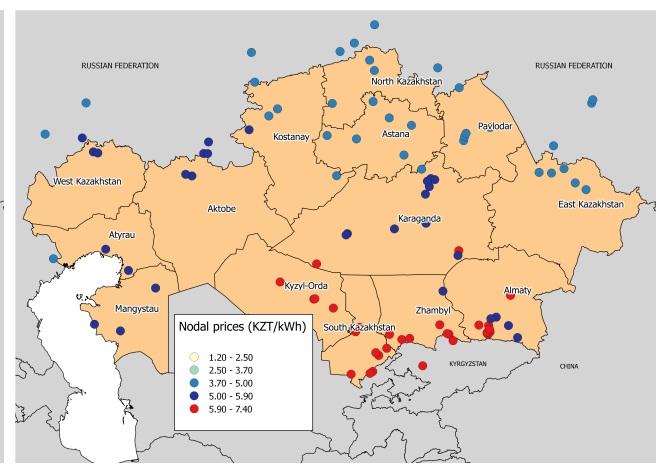

Figure 8: Winter hour with peak demand 


\subsection{Zonal pricing in Kazakhstan}

The scenario with zonal pricing discusses a market design which relies on power exchanges and bidding zones, representing more closely the European power sector. Compared to the regional definition in Figure 1 the zonal scenario assumes Karaganda region as additional bidding zone separating it from the North. This is done to account for network congestion and the characteristic of Karaganda region as transit hub between the North and South (see Figure 11). The assumptions are: the trade capacity (NTC value) between the price zones North-Middle and Middle-South is $1500 \mathrm{MW}$ each. To represent transmission losses in the zonal market design, trades between North-Middle (Middle-South) have to provide an additional $4 \%(8 \%)$ of the trade volume for losses. This representation of losses is not common in zonal markets but it could be a reasonable assumption for systems with long-distance transmission lines and high transmission losses.

Table 4 below indicates generation results and inter-zonal trade (results are scaled to the annual level). The zonal results show once again the high dependency on electricity generation in the North and the resulting trade flows and losses. ${ }^{9}$

\begin{tabular}{|c|c|c|c|c|c|c|}
\hline [TWh] & & North & Middle & South & West & Total \\
\hline \multirow{4}{*}{ Data input } & Consumption & $\overline{45.9}$ & 15.5 & $\overline{c 19.6}$ & $\overline{10.3}$ & $\overline{91.4}$ \\
\hline & Imports & -1.22 & & -0.25 & -0.05 & \\
\hline & Exports & 0.9 & & 0.25 & 0.05 & \\
\hline & Total demand & 45.6 & 15.5 & 19.6 & 10.3 & 90.9 \\
\hline \multirow{8}{*}{ Results on generation } & Coal & 31.5 & 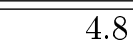 & & & \\
\hline & Coal CHP & 18.9 & 7.6 & 3.6 & & \\
\hline & Gas & & 0.3 & 0.9 & 3.8 & \\
\hline & Gas CHP & 0.7 & & 1.1 & 6.6 & \\
\hline & Hydro & 9.7 & & 4.7 & & \\
\hline & Wind & 0.1 & & 0.02 & & \\
\hline & PV & & & 0.07 & & \\
\hline & Generation & 59.0 & 12.7 & 10.4 & 10.3 & 92.3 \\
\hline \multirow{4}{*}{ Results on zonal exchange } & Inflow & & -13.1 & -9.6 & & \\
\hline & Outflow & 13.1 & 9.6 & & & \\
\hline & Balance & 13.1 & -3.5 & -9.6 & & \\
\hline & Losses & 0.3 & 0.6 & 0.4 & & 1.3 \\
\hline
\end{tabular}

Table 4: Zonal input data and results on zonal generation and inter-zonal flows

Zonal prices in the West (Figure 9) remain constant over the entire year at about $5.5 \mathrm{KZT} / \mathrm{kWh}$, representing the marginal generation costs of gas-fired power plants. The deviation in prices around this values for some nodes results from network losses within the bidding zone which are not represented in the zonal scenario. The average hourly nodal price (weighted with nodal demand) from the nodal results is well in line with the zonal price in the zonal scenario.

A similar pattern in terms of hourly price stability results in the North, yet at a significantly lower level of about $1.3 \mathrm{KZT} / \mathrm{kWh}$. This price reflects marginal generation costs of the electricity only coal-fired power plants. Whereas the zonal price is close to the average nodal price of about $1.4 \mathrm{KZT} / \mathrm{kWh}$ in the summer, it underestimates average nodal prices of about $1.6 \mathrm{KZT} / \mathrm{kWh}$ during day-time in the winter when nodal prices ranges from 1.3-2.0 KZT/kWh in the North. Therefore, prices in the zonal scenario do not cover for the entire short-run cost from power generation and inter-zonal network losses.

\footnotetext{
${ }^{9}$ The losses in the zonal scenario should not be misunderstood as technical network losses. Following the large geographic distances between the zones the methodology assumes a loss factor for inter-zonal trade in the zonal market design.
} 


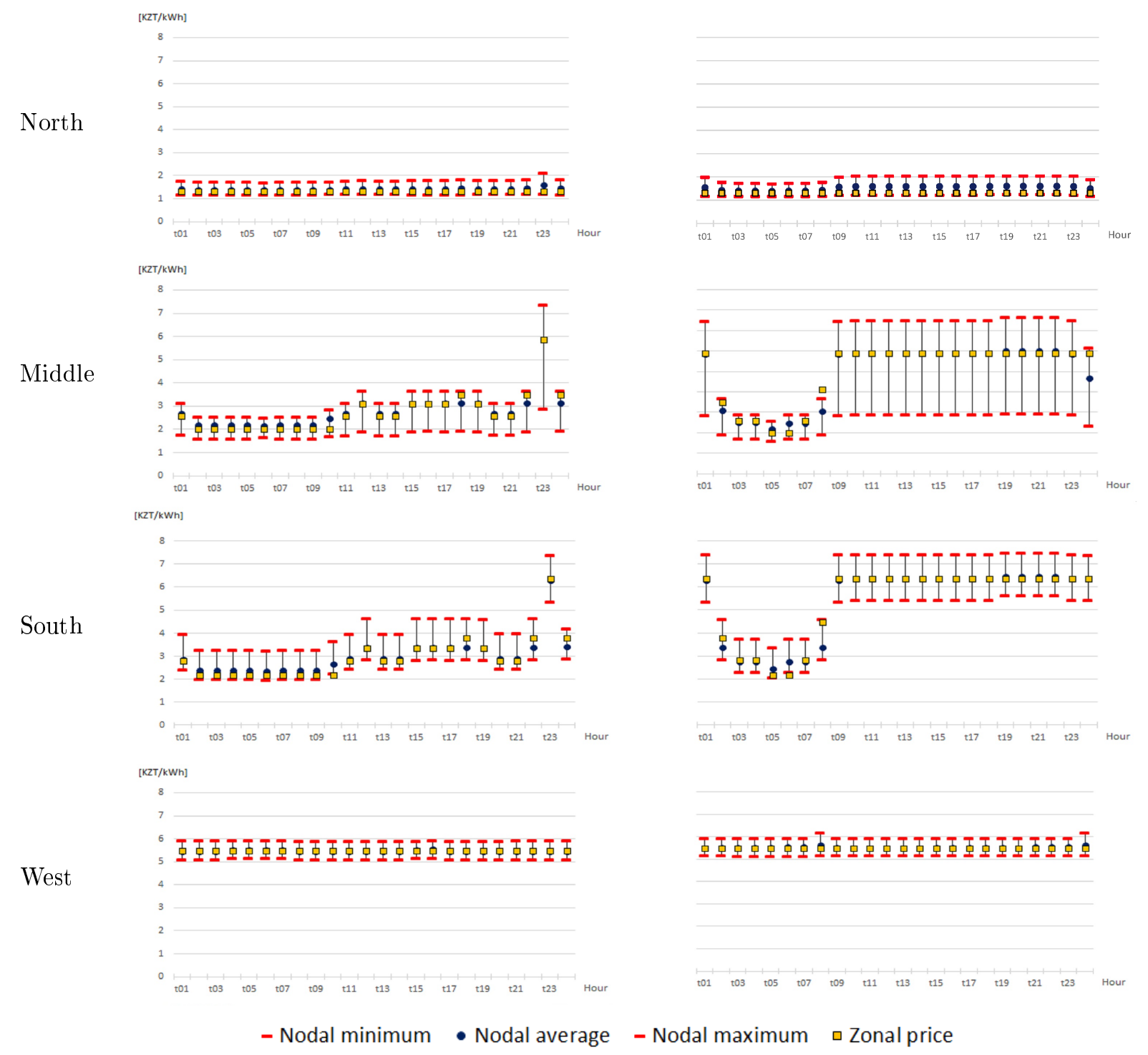

Figure 9: Hourly zonal price and nodal prices in each zone for one summer and winter day

Hourly patterns of zonal prices in the Middle and South varies significantly from the North. During night-time, the constraint on the inter-zonal NTC capacity between North and Middle is binding in all hours, resulting in prices of about $2.0 \mathrm{KZT} / \mathrm{kWh}$ in the Middle. This price reflects the marginal generation costs of local coal-fired power plants and the slightly higher prices in the South account for the additional loss factor. Binding NTC capacity from the North together with higher electricity demand during the day causes significant higher price spreads. Prices in the Middle and South range between $2.8-3.8 \mathrm{KZT} / \mathrm{kWh}$ in the summer (even higher for peak demand) and between $5.9-6.3 \mathrm{KZT} / \mathrm{kWh}$ in the winter. While zonal prices are close to average nodal prices for most hours, there are deviations in some hours (questioning the right choice for the NTC level for that particular hour). Extreme variations for nodal prices in the South and in particular in the Middle could be an indicator for additional internal bottlenecks within the zones or insufficient representation of transmission losses in the zonal market representation.

All in all, zonal results for the electricity system of Kazakhstan are promising but also indicate the short- 
comings of the zonal design in relation to the first best of nodal pricing. The strict geographic orientation of the Kazakh transmission network from North to South makes Kazakhstan more suitable for bidding zones than for example a highly meshed system, but comparatively high transmission losses have to be considered sufficiently.

\section{Conclusion}

In this paper we present a comprehensive techno-economic model of the Kazakh electricity system. It is the first model of the electric system in Kazakhstan to be based on publicly available data including power plants and the transmission infrastructure in such detail. The model can be applied for spatial analysis of the sector focusing on the operational level of power plants as done in this paper. The hourly nodal least-cost generation dispatch in Kazakhstan allows for insights in regional scarcity and related electricity prices and provides a better understanding for the interdependency of generation and transmission. The models results also indicate the value of the north-south integration in Kazakhstan. However, due to the strong regional concentration of generation capacity, the interconnection remains congested in many winter hours causing a high north-south differential in market prices. The analysis of the zonal pricing scenario (contrary to nodal pricing) indicates a possible alternative for the market-based restructuring of the power sector even though the implementation of losses remain challenging in that market scheme.

In general, the model provides a flexible techno-economic tool that can be adapted to analyze investments and placing of new generation capacity-especially for wind and solar power-and the model results can provide information for expansion planning in the transmission network. The techno-economic character of the model also allows for its employment to research questions on changes in the market design, e.g., towards a more market-based approach. Nodal price deviations in the model results suggest strong implications in case of a change towards a more market-based system. Zonal or nodal pricing schemes could set strong incentives for investment in the South of the country where both wind and PV resources are vastly available.

If Kazakhstan decides to embark on a pathway towards a more renewable-based system the issue of providing district heat for a large share of the population during the long and severe winter period will play a critical role. The current model formulation only provides a simplified representation of district heat but the model could be extended to include more details on the heat sector and its connection to electricity supply. While the current political situation has a tendency towards self-sufficiency of the Central Asian republics the "Concept of a single Eurasian Power Market" provides space for large synergies between the different riparian countries. Expanding the model to include more details on the energy systems of the Central Asian countries would provide an important tool to quantify resulting synergies.

With its aging generation fleet, growing population and urbanization, and its vast renewable potential Kazakhstan is at the cross-roads of setting-up its energy future and this paper provide a first step in developing useful transparent techno-economic tools to quantify implications of different pathways for the future power system.

\section{Acknowledgements}

This paper is part of a broader cooperation effort between DIW Berlin, DIW Econ, National Laboratory Astana and the Nazarbayev University on the energy system in Kazakhstan. Initial work was performed in the NAMAs Central Asia project and later continued in mutual visits and workshops. We would like to gratefully acknowledge Yerbol Akhmetbekov, Christian von Hirschhausen, Franziska Holz, and Petra Opitz for their valuable input in discussions and for providing institutional support to the team. 


\section{References}

ABIT Associates, Stokholm Environment Institute, and Nazar Businesa and Technology LLC (2014): Economics of Climate Change in central and West Asian-Mitigation Component. Technical assistance Consultant's Report. Tech. rep.

Abrell, J. and Rausch, S. (2016): Cross-country electricity trade, renewable energy and European transmission infrastructure policy. Journal of Environmental Economics and Management, 79: 87-113. 10.1016/j.jeem.2016.04.001.

Allevi, E., Bonenti, F., and Oggioni, G. (2013): Complementarity models for restructured electricity markets under environmental regulations. Tech. rep.

Antipova, E., Zyryanov, A., McKinney, D., and Savitsky, A. (2002): Optimization of Syr Darya Water and Energy Uses. Water International, 27(4): 504-516. 10.1080/02508060208687038.

Atakhanova, Z. and Howie, P. (2007): Electricity demand in Kazakhstan. Energy Policy, 35(7): 3729-3743. 10.1016/j.enpol. 2007.01 .005

Babu, M. R. and Harini, D. (2016): LP based solution for Security Constrained Optimal Power Flow. 355-359. IEEE. 10.1109/ICONSTEM.2016.7560976.

Capros, P., Mantzos, L., Kolokotsas, D., Ioannou, N., Georgakopoulos, T., and Filippopoulitis, A. (1998): The PRIMES Energy System Model. Reference manual. Tech. rep., National Technical University of Athens, Athens, Greece.

Chen, Y. and Wang, L. (2013): Renewable Portfolio Standards in the Presence of Green Consumers and Emissions Trading. Networks and Spatial Economics, 13(2): 149-181. 10.1007/s11067-012-9176-0.

Committee of Statistics of Kazakhstan (2015): Socio-economic development of the Republic of Kazakhstan. Tech. rep., Astana, Kazakhstan.

Criqui, P. (1996): International markets and energy prices : the POLES model. Tech. rep., London, New York.

Davidson, M. R., Zhang, D., Xiong, W., Zhang, X., and Karplus, V. J. (2016): Modelling the potential for wind energy integration on China's coal-heavy electricity grid. Nature Energy, 1: 16086.

De Miglio, R., Akhmetbekov, Y., Baigarin, K., Bakdolotov, A., and Tosato, G. (2014): Cooperation benefits of Caspian countries in their energy sector development. Energy Strategy Reviews, 4: 52-60. 10.1016/j.esr.2014.09.002.

Deane, J., Chiodi, A., Gargiulo, M., and O Gallachoir, B. P. (2012): Soft-linking of a power systems model to an energy systems model. Energy, 42(1): 303-312. 10.1016/j.energy.2012.03.052.

Després, J., Hadjsaid, N., Criqui, P., and Noirot, I. (2015): Modelling the impacts of variable renewable sources on the power sector: Reconsidering the typology of energy modelling tools. Energy, 80: 486-495. 10.1016/j.energy.2014.12.005.

Egerer, J. (2016): Open source Electricity Model for Germany (ELMOD-DE). Data Documentation 83, DIW Berlin, Berlin, Germany.

Egerer, J., Mendelevitch, R., and von Hirschhausen, C. (2014): A Lower Carbon Strategy for the Electricity Sector of Kazakhstan to 2030/50 - Scenarios for Generation and Network Development. Politikberatung kompakt 85, DIW Berlin, Berlin, Germany.

Ehrenmann, A. and Smeers, Y. (2011): Generation Capacity Expansion in a Risky Environment: A Stochastic Equilibrium Analysis. Operations Research, 59(6): 1332-1346. 10.1287/opre.1110.0992.

ENEGRYPROM.KZ (2016): Daily news article "Power generation reaches $53.7 \mathrm{bn}$ kWh in January-July, up by $1.7 \%$ year on year. Gas turbine power plants with a capacity of $100,000 \mathrm{~kW}$ worth KZT18.6bn were commissioned in the first half of the year".

Faibisovich, D., Karapetyan, E., and Shapiro, E. (2006): Справочник по проектированию электрических сетей (Еlесtrical network design guide). Tech. rep., Moscow, Russia.

Fang, T. and Lahdelma, R. (2016): Optimization of combined heat and power production with heat storage based on sliding time window method. Applied Energy, 162: 723-732. 10.1016/j.apenergy.2015.10.135.

Finon, D. (1981): Scope and limitations of formalized optimization of a national energy system-the EFOM model. Tech. rep., Brussel, Belgium.

Fishbone, L. G. and Abilock, H. (1981): Markal, a linear-programming model for energy systems analysis: Technical description of the bnl version. International Journal of Energy Research, 5(4): 353-375. 10.1002/er.4440050406.

Gómez, A., Dopazo, C., and Fueyo, N. (2014): The causes of the high energy intensity of the Kazakh economy: A characterization of its energy system. Energy, 71: 556-568. 10.1016/j.energy.2014.04.102.

Goldstein, G. and Tosato, G. (2008): Global Energy Systems and Common Analyses. Final Report of Annex X(2005-2008). Tech. rep.

Gürkan, G. and Langestraat, R. (2014): Modeling and analysis of renewable energy obligations and technology bandings in the UK electricity market. Energy Policy, 70: 85-95. 10.1016/j.enpol.2014.03.022.

Hall, L. M. and Buckley, A. R. (2016): A review of energy systems models in the UK: Prevalent usage and categorisation. Applied Energy, 169: 607-628. 10.1016/j.apenergy.2016.02.044.

Heaps, C. (2008): An introduction to LEAP. Tech. rep.

Helseth, A. (2012): A linear optimal power flow model considering nodal distribution of losses. 1-8. IEEE. 10.1109/EEM.2012. 6254717 .

Hu, Z., Cheng, H., Yan, Z., and Li, F. (2010): An Iterative LMP Calculation Method Considering Loss Distributions. IEEE Transactions on Power Systems, 25(3): 1469-1477. 10.1109/TPWRS.2010.2041799.

Huppmann, D. and Egging, R. (2014): Market power, fuel substitution and infrastructure - A large-scale equilibrium model of global energy markets. Energy, 75: 483-500. 10.1016/j.energy.2014.08.004.

HydroMetCenter, R. F. (2012): Historical weather data for Russia and CIS. Tech. rep.

Inyutina, L., Salytuina, Y., Sultankulova, A., and Flessa, A. (2012): Mitigation/Adaptation scenario and Climate Change policy portfolios for Republic of Kazakhstan. Tech. rep., Astana, Kazakhstan. 
JSC Samruk-Energy (2016): Annual report 2015 (vol. 1). Tech. rep., Astana, Kazakhstan.

Karatayev, M. and Clarke, M. L. (2016): A review of current energy systems and green energy potential in Kazakhstan. Renewable and Sustainable Energy Reviews, 55: 491-504. 10.1016/j.rser.2015.10.078.

Kazakh government (2000): Постановление о дополнительных мерах по повышению эффективности оптового рынка электрической энергии и мощности Республики Казахстан №606 (Decree on supplementary measures on increasing the efficiency of the wholesale market for electric energy and power in the Republic of Kazakhstan). Tech. rep., Astana, Kazakhstan.

Kazakh government (2013a): Приказ об утверждении Правил утверждения тарифов (цен, ставок сборов) и тарифных смет на регулируемые услуги (товары, работы) субъектов естественных монополий №8642 (On approval of regulations on ratification of tariffs).

Kazakh government (2013b): Concept for transition of the Republic of Kazakhstan to Green Economy. Tech. rep., Astana, Kazakhstan.

Kazakh Institute of Climate and Environment Monitoring (1996): Kazakhstan Greenhouse Gas Mitigation Assessment. Report. Tech. rep.

KAZENERGY Association (2014): Обзор государственной политики Республики Казахстан в области энергосбережения и повышения энергоэффективности (Review of the policy of Kazakhstan in the field of energy saving and energy efficiency).

KAZENERGY Association (2016): The National Energy Report 2015. Tech. rep., Astana, Kazakhstan.

KEGOC (2014a): Обзор. Работа электроэнергетической отрасли Казахстана в 2013 году (Review. The current status of the power supply sector in 2013). Tech. rep., Astana, Kazakhstan.

KEGOC (2014b): Баланс электроэнергии ЕЭС Казахстана до 2021 года (Power generation balance forecast till 2021). Tech. rep., Astana, Kazakhstan.

KEGOC (2014c): Карта-схема электрических сетей 1150-500-220-110 кВ. ЕЭС Республики Казахстан (Еlectricity Network Overhead Lines of Kazakhstan). Tech. rep., Astana, Kazakhstan.

KEGOC (2016): Annual report for 2015. Tech. rep., Astana, Kazakhstan.

Kerimray, A., Baigarin, K., De Miglio, R., and Tosato, G. (2016): Climate change mitigation scenarios and policies and measures: the case of Kazakhstan. Climate Policy, 16(3): 332-352. 10.1080/14693062.2014.1003525.

Kiessling, F., Nefzger, P., Nolasco, J. F., and Kaintzyk, U. (2003): Overhead Power Lines. Power Systems. Springer Berlin Heidelberg, Berlin, Heidelberg.

Koltsaklis, N. E., Dagoumas, A. S., Kopanos, G. M., Pistikopoulos, E. N., and Georgiadis, M. C. (2014): A spatial multiperiod long-term energy planning model: A case study of the Greek power system. Applied Energy, 115: 456-482. 10.1016/j.apenergy.2013.10.042.

Konkakov, A. and Kubayeva, G. (2016): Progress in diversification of the economy in Kazakhstan. Working paper No. $2016 / 8$. Tech. rep., Astana, Kazakhstan.

KOREM (2016a): Предельные тарифы на электроэнергию 2016-2018 гг (Marginal prices of power plants for 2016-2018 y.). Tech. rep., Astana, Kazakhstan.

KOREM (2016b): Annual report 2015 of Kazakhstan electricity and power market operator. Tech. rep., Astana, Kazakhstan.

Kunz, F. and Zerrahn, A. (2015): Benefits of coordinating congestion management in electricity transmission networks: Theory and application to Germany. Utilities Policy, 37: 34-45. 10.1016/j.jup.2015.09.009.

Leuthold, F. U., Weigt, H., and von Hirschhausen, C. (2012): A Large-Scale Spatial Optimization Model of the European Electricity Market. Networks and Spatial Economics, 12(1): 75-107. 10.1007/s11067-010-9148-1.

McKinney, D. and Savitsky, A. G. (2001): EPIC Modeling System Guide. Water, Salt \& Energy Management Problems. Tech. rep.

McKinsey (2012): Data on the price for electricity from power plants (including fuel and transport costs). Tech. rep.

Mikkola, J. and Lund, P. D. (2016): Modeling flexibility and optimal use of existing power plants with large-scale variable renewable power schemes. Energy, 112: 364-375. 10.1016/j.energy.2016.06.082.

Nahmmacher, P., Schmid, E., Hirth, L., and Knopf, B. (2016): Carpe diem: A novel approach to select representative days for long-term power system modeling. Energy, 112: 430-442. 10.1016/j.energy.2016.06.081.

NASA (2005): Surface meteorology and Solar Energy: Daily Averaged Data. Tech. rep.

Neuhoff, K., Hobbs, B., and Newbery, D. M. (2011): Congestion Management in European Power Networks: Criteria to Assess the Available Options. Discussion papers 1161, DIW Berlin, Berlin, Germany.

OECD (2014): Energy subsidies and climate change in Kazakhstan (Final draft Report). Tech. rep.

OECD/IEA (2016): Clean Energy Technology Assessment Methodology Pilot Study. Kazakhstan. Tech. rep., Paris, France.

Pfenninger, S., Hawkes, A., and Keirstead, J. (2014): Energy systems modeling for twenty-first century energy challenges. Renewable and Sustainable Energy Reviews, 33: 74-86. 10.1016/j.rser.2014.02.003.

Razeghi, G., Brouwer, J., and Samuelsen, S. (2016): A spatially and temporally resolved model of the electricity grid - Economic vs environmental dispatch. Applied Energy, 178: 540-556. 10.1016/j.apenergy.2016.06.066.

Rintamäki, T., Siddiqui, A. S., and Salo, A. (2016): How much is enough? Optimal support payments in a renewable-rich power system. Energy, 117: 300-313. 10.1016/j.energy.2016.10.058.

Santos, T. N. and Diniz, A. L. (2011): A Dynamic Piecewise Linear Model for DC Transmission Losses in Optimal Scheduling Problems. IEEE Transactions on Power Systems, 26(2): 508-519. 10.1109/TPWRS.2010.2057263.

Sarbassov, Y., Kerimray, A., Tokmurzin, D., Tosato, G., and De Miglio, R. (2013): Electricity and heating system in Kazakhstan: Exploring energy efficiency improvement paths. Energy Policy, 60: 431-444. 10.1016/j.enpol.2013.03.012.

Schweppe, F. C., Caramanis, M. C., Tabors, R. D., and Bohn, R. E. (1988): Spot Pricing of Electricity. Springer US, Boston (MA), United States.

Supreme Eurasian Economic Council (2015): Концепция формирования общего электроэнергетического рынка 
Евразийского экономического союза (Concept of a Single Eurasian Power Market). Tech. rep., Moscow, Russia. Uatkhanov, Y. (2016): Kazakhstan Ministry of Energy Introduces Renewable Energy Auctions.

Ventosa, M., Baillo, A., Ramos, A., and Rivier, M. (2005): Electricity market modeling trends. Energy Policy, 33(7): 897-913. 10.1016/j.enpol.2003.10.013.

Zerrahn, A. and Schill, W.-P. (2015): A greenfield model to evaluate long-run power storage requirements for high shares of renewables. Discussion papers 1457, DIW Berlin, Berlin, Germany.

Zhang, J., Dobson, I., and Alvarado, F. (2004): Quantifying transmission reliability margin. International Journal of Electrical Power ES Energy Systems, 26(9): 697-702. 10.1016/j.ijepes.2004.05.002.

Zhang, Z. J., Goodwin, D., and Nair, N.-K. C. (2013): Analysis of transmission loss model in New Zealand Electricity Market dispatch. 1-5. IEEE. 10.1109/AUPEC.2013.6725430. 


\section{Appendix}

\begin{tabular}{|c|c|c|}
\hline Notation & Description & Unit \\
\hline \multicolumn{3}{|l|}{ Indices } \\
\hline$l \in L$ & transmission lines & \\
\hline$n, k \in N$ & network nodes & \\
\hline$p \in P$ & generation units & \\
\hline$t \in T$ & time periods (hours) & \\
\hline$w \in T$ & time periods (weeks) & \\
\hline \multicolumn{3}{|l|}{ Sets } \\
\hline $\mathrm{L}$ & set of all transmission lines & \\
\hline $\mathrm{N}$ & set of all network nodes & \\
\hline $\mathrm{P}$ & set of all generation units & \\
\hline $\mathrm{T}$ & set of all time periods & \\
\hline \multicolumn{3}{|c|}{ Parameters } \\
\hline$A_{l n}$ & adjacent matrix between line 1 and node $n$ & \\
\hline$A V_{p t}$ & seasonal availability of generation unit $\mathrm{p}$ & $\%$ \\
\hline$B_{n k}$ & network susceptance matrix & \\
\hline$C A P_{l}^{\mathrm{L}}$ & maximum capacity of line 1 & MW \\
\hline$C A P_{p}^{\mathrm{P}+}$ & maximum capacity of generation unit $p$ & MW \\
\hline$C A P_{p}^{\mathrm{P}-}$ & minimum operational capacity of generation unit $\mathrm{p}$ in period $\mathrm{t}$ & MW \\
\hline$C A P_{p t}^{\mathrm{H}-}$ & $\begin{array}{l}\text { minimum operational capacity of a generation unit } \mathrm{p} \\
\text { in time period } \mathrm{t} \text { due to must-run of CHP }\end{array}$ & MW \\
\hline$D E M_{n t}$ & electricity demand in node $\mathrm{n}$ in time period $\mathrm{t}$ & MW \\
\hline$E X_{n t}$ & potential export in node $\mathrm{n}$ in time period $\mathrm{t}$ & MW \\
\hline$H_{l n}$ & flow sensitivity matrix & \\
\hline$I M_{n t}$ & potential import in node $\mathrm{n}$ in time period $\mathrm{t}$ & MW \\
\hline$L C_{l}$ & loss coefficient for each line & \\
\hline$M C_{p}$ & marginal generation costs for conventional generation unit $\mathrm{p}$ & $\mathrm{KZT} / \mathrm{MW}$ \\
\hline$R E S_{n t}$ & renewable generation level in node $\mathrm{n}$ in time period $\mathrm{t}$ & MW \\
\hline$V O L L$ & cost of lost load & $\mathrm{KZT} / \mathrm{MW}$ \\
\hline \multicolumn{3}{|c|}{ Positive Variables } \\
\hline$e n_{p t}$ & electricity generation from unit $\mathrm{p}$ in time period $\mathrm{t}$ & MW \\
\hline$e n s_{n t}$ & energy not served in node $n$ in time period $t$ & MW \\
\hline $\operatorname{loss}_{l t}^{+/-}$ & value of line losses in line 1 in time period $t$ & MW \\
\hline \multicolumn{3}{|l|}{ Variables } \\
\hline$c$ & variable generation cost of the electricity dispatch & $\mathrm{KZT}$ \\
\hline$n i_{n t}$ & net input from the transmission network & MW \\
\hline$p f_{l t}$ & line flow of line 1 in time period $t$ & MW \\
\hline$\theta_{n t}$ & Phase angle difference in respect to slack bus $\hat{n}$ & \\
\hline
\end{tabular}

\section{Binary Variables}

on $n_{p t} \quad 1$, if generation unit $\mathrm{p}$ is in operation in the time period $\mathrm{t}$

Table 5: Notation of the electricity sector model 


\section{Assumption on input data}

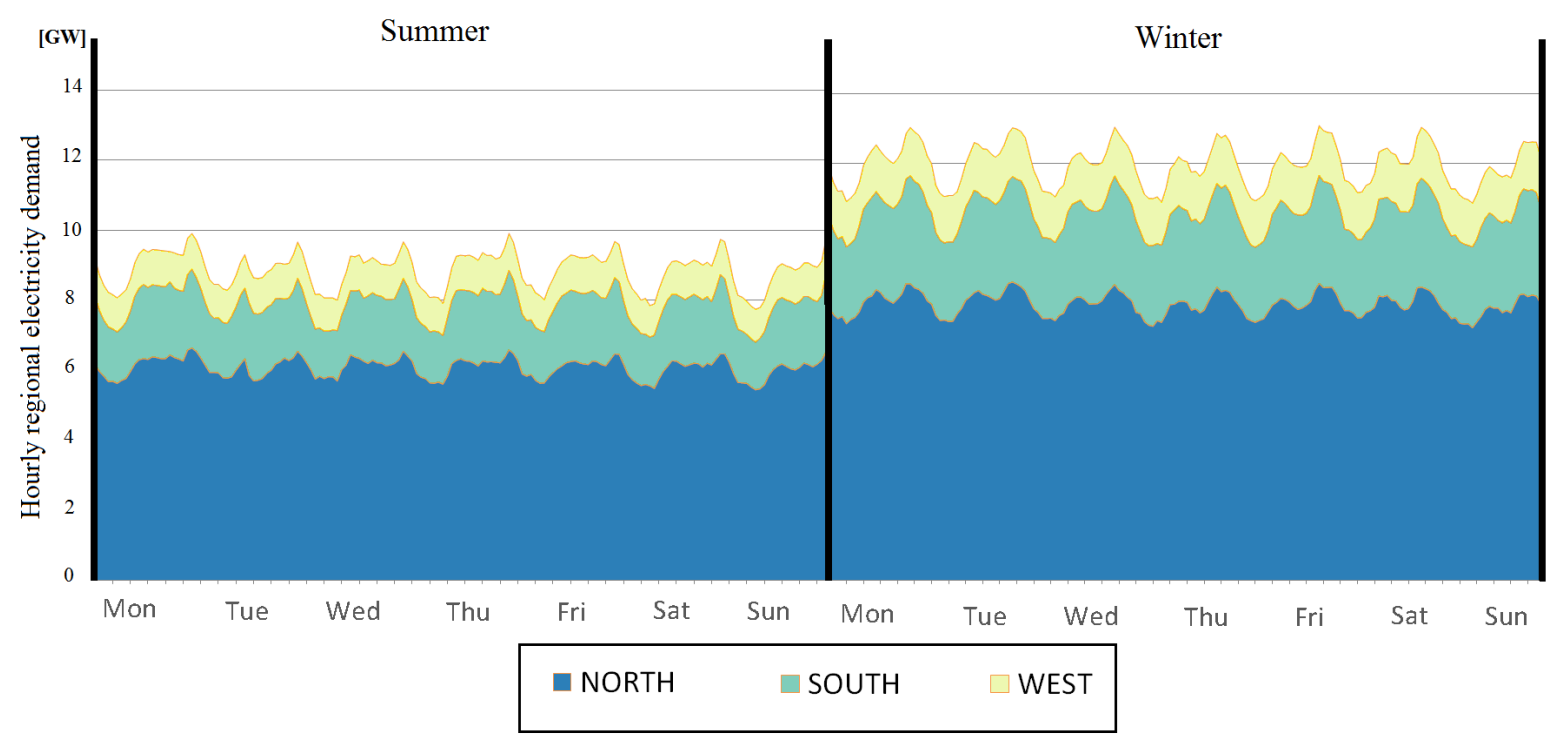

Figure 10: Hourly demand in winter and summer week with zonal distribution

\section{Regional distribution of generation}

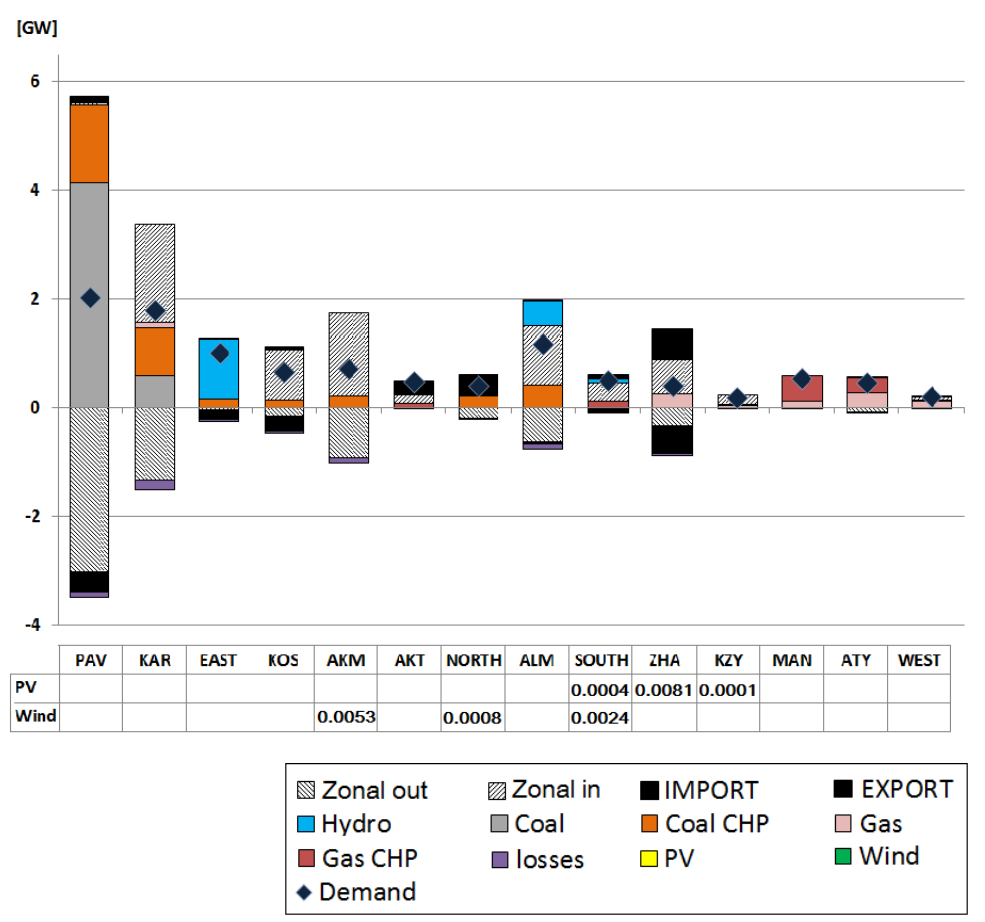

Figure 11: Average electricity generation, demand and import/export flows by region 